\title{
Commercialization and the Decline of Joint Liability Microcredit ${ }^{\text {th }}$
}

\author{
Jonathan de Quidtat, ${ }^{\mathrm{a},}$ Thiemo Fetzer ${ }^{\mathrm{b}}$, Maitreesh Ghatak ${ }^{\mathrm{c}}$ \\ ${ }^{a}$ Institute for International Economic Studies and CESifo. Address: Institute for \\ International Economic Studies, Stockholm University, 10691 Stockholm, Sweden. \\ ${ }^{b}$ University of Warwick. Address: University of Warwick, Department of Economics, \\ Coventry CV4 7AL, United Kingdom. \\ ${ }^{c}$ London School of Economics. Address: Department of Economics, London School of \\ Economics and Political Science, London WC2A 2AE, United Kingdom.
}

\begin{abstract}
Numerous authors point to a decline in joint liability microcredit, and rise in individual liability lending. But empirical evidence is lacking, and there have been no rigorous analyses of possible causes. We first show using the wellknown MIX Market dataset that there is evidence for a decline. Second, we show theoretically that commercialization-an increase in competition and a shift from non-profit to for-profit lending (both of which are present in the data)-drives lenders to reduce their use of joint liability loan contracts. Third, we test the model's key predictions, and find support for them in the data.
\end{abstract}

JEL codes: G21, O12, O16

Keywords: microfinance, joint liability, commercialization, market structure

\footnotetext{
"de Quidt acknowledges financial support from Handelsbanken's Research Foundations, grant no: B2014-0460:1. Ghatak would like to thank DFID-ESRC Growth Research Programme (DEGRP) Grant ES/L012103/1 for financial support. Declarations of interest: none. ${ }^{*}$ Corresponding author.

Email addresses: jonathan.dequidt@iies.su.se (Jonathan de Quidt), t.fetzer@warwick.ac.uk (Thiemo Fetzer), M.Ghatak@lse.ac.uk (Maitreesh Ghatak)
} 


\section{Introduction}

Microfinance Institutions (MFIs), and in particular Muhammad Yunus' Grameen Bank, have long attracted the interest of economists for their success in lending to poor borrowers written off as uncreditworthy by traditional lenders. A large literature analyzes the innovative contractual tools used by MFIs to achieve this, of which the best known is joint liability lending (JL), whereby the borrower and one or more group members assume liability for one another's debts. Joint liability has been shown to be able to overcome problems of adverse selection, moral hazard and limited enforcement, leveraging social collateral that can substitute for the conventional collateral that the poor, by definition, lack. ${ }^{1}$

In the recent literature it has become common to see claims of a wide-spread decline in the use of $\mathrm{JL}^{2}{ }^{2}$ Yet such claims are anecdotal, typically pointing to high-profile examples such as Grameen, BancoSol, and ASA who initially pioneered the use of joint liability credit yet have since moved to an individual liability (IL) lending model. Moreover, we are aware of no satisfactory account of what has changed about the lending environment to reverse the initial success of JL.

We make two contributions. First, we show empirically that there has indeed been a trend away from JL in recent years. To do this we use an MFI-level panel from the well-known data collected by the MIX Market, covering the years 20082014. This data source is unique in containing the crucial lending methodology information needed for our analysis.

Second, we argue theoretically and empirically that the trend can be explained, at least in part, by commercialization. By commercialization, we refer to two forces: increases in for-profit lending, and increased competition. First, as we document, the microcredit industry has shifted from being largely made up of non-profit and NGO lenders to an increasingly for-profit marketplace. In

\footnotetext{
${ }^{1}$ For a detailed review of both the theory and history of JL, see Ghatak and Guinnane (1999) and Armendáriz de Aghion and Morduch (2010).

${ }^{2}$ E.g. Hermes and Lensink (2007), Armendáriz de Aghion and Morduch (2010), Giné et al. (2011), Breza (2013), Feigenberg et al. (2013), Carpena et al. (2013), Giné and Karlan (2014).
} 
our model, non-profits and for-profits target different objective functions, and thus behave differently in equilibrium. Second, competition among lenders for borrowers has increased, leading to an expansion of the sector. In our model, competition improves borrowers' outside options in case of default, by making it easier to find another lender. ${ }^{3}$

We present a simple model that makes three empirical predictions. First, for-profit lenders are less likely to use JL than non-profits. Second, competition induces non-profits to switch from JL to IL. Third, in contrast to the broad trend, competition induces for-profits to switch from IL to JL. While the three effects are not all in the same direction, the net effect is such that beginning from an uncompetitive, largely non-profit market, increasing competition and increasing the for-profit share in the market both lead to increases in the use of IL.

Intuitively, the main driving force in our model is that JL involves tighter incentive constraints than IL, since in some states of the world, it involves not only repaying one's own loan, but also helping a group member repay her loan. At the same time, the advantage of JL is, because any given loan gets repaid with greater probability, the borrower gets to maintain access to credit from the lender, and depending on the market structure, the interest rate could go down. Non-profits choose whatever lending arrangement has higher borrower welfare, subject to the incentive constraints and a break-even constraint. The theory implies that JL maximizes borrower welfare, so non-profits offer JL whenever they can break even while doing so. Competition tends to reduce their use of JL as it improves the borrower's outside option, namely the possibility of obtaining a new loan if she defaults at her current lender. This reduces the cost of losing her existing contract and thus tightening the more demanding incentive constraint, namely, that under JL. The for-profit also requires JL to break even, but additionally it must be more profitable than IL. Since this is a

\footnotetext{
${ }^{3}$ We also show in an extension that our qualitative predictions hold under alternative notions of competition.
} 
stricter condition, the for-profit ends up offering JL to fewer borrowers. Finally, as competition increases, for-profits tend to use JL more (unlike non-profits) as revenue under JL is less sensitive to the borrower's outside option than under IL. We show that the qualitative conclusions of the theory are robust to other effects of competition, such as imposing constraints on lenders' ability to charge high interest rates at the loan offer stage.

We then test the implications of the model empirically, exploiting withinregion, within-country and within-MFI variation in lenders' for-profit status and lending methodology. We lack direct measures of the level of competition in the microcredit market, so instead we use proxy measures that try to capture access to and depth of financial markets in the country in general, rather than microcredit in particular. Our identifying assumption is that these measures are valid proxies for borrowers' outside options in the microcredit sector, either because the formal sector competes with the microcredit sector or because the proxies reflect underlying developments that make it easier for borrowers to access alternative forms of finance. We find that for-profit lenders indeed tend to use JL less than non-profits. We find strong support for the prediction that JL usage by for-profits is increasing in our competition proxy. Although the data are more supportive of no response than the predicted overall negative effect, we do find robustly that non-profits do not increase JL usage when competition increases, i.e. they respond qualitatively differently to for-profits in the predicted direction.

With the data available we cannot perfectly resolve the issue of identification, but we perform a number of robustness checks. Our findings are robust to two panel definitions (strongly balanced and weakly balanced), to the inclusion of a broad range of controls, interactions and fixed effects. They also hold up when we replace our long panel with a shorter one containing more MFIs and countries, which also contains alternative measures of IL and JL usage intensity. ${ }^{4}$

\footnotetext{
${ }^{4}$ Our main dataset uses data provided to us by Chris Ahlin, who uses it in Ahlin and Suandi (2018), a paper we discuss below. These data are preferred because of their long coverage, from 2008-2014, but they only contain measures of IL usage by number of loans, not by value.
} 
We take further comfort from the fact that the model's prediction for for-profits' response to changes in competition-which is strongly supported in the data-is in the opposite direction to overall trends and therefore we think provides a strong test of the theory.

Our theory fits into a branch of the literature that highlights the leverage of social capital, especially through JL lending, as a key feature of microcredit. ${ }^{5}$ Our model explains changes in the use of JL via changes in the level of social capital required for an MFI to be willing to offer JL. Since we cannot observe social capital, our main identifying assumption is that changes in the unobservable social environment are uncorrelated with changes in the market structure and competitive environment, conditional on our various controls and fixed effects. At least in the short run, we believe that this is a plausible assumption.

We are not in fact the first to note an association between commercialization and the decline of JL. Karlan and Zinman (2009a) write: ${ }^{6}$

[T] he industrial organization of microcredit is trending toward something that looks more like the cash loan market: for-profit, more competitive delivery of untargeted, individual liability loans... This evolution is happening from both the bottom-up (non-profits converting to for-profits) and the top-down (for-profits expanding into subprime and consumer segments).

However to our knowledge we are the first to outline the theoretical and empirical case for a causal relationship from the former to the latter.

In related work, Cull et al. (2009) use an early version of the MIX Market data to provide a descriptive overview of the microcredit industry. Notably, they observe that non-profits are more likely than for-profits to use JL lending

Our alternative dataset is a shorter panel, also from the MIX, covering 2008-2011, and is the dataset used in prior circulated versions of this paper. It is valuable for robustness checking because it contains more MFIs as well as data on IL lending by value.

${ }^{5}$ E.g. Besley and Coate (1995), Ghatak and Guinnane (1999), Karlan (2005), Karlan (2007), Ahlin and Townsend (2007), Cassar and Wydick (2010), de Quidt et al. (2016), de Quidt et al. (in press).

${ }^{6}$ See also Karlan and Zinman (2009b). 
methods, as our model predicts and as we also observe in our chronologically later and larger sample. McIntosh et al. (2005) show empirically that increasing competition between lenders in Uganda harmed repayment performance, in line with the mechanism proposed in our paper (they put more weight on a multiple borrowing interpretation than weakened repayment incentives, though the latter naturally goes hand in hand with the former; our model features only the second channel). Baquero et al. (forthcoming), use proprietary rating agency data on microfinance institutions to study the effect of market concentration on interest rates in sector, finding that non-profits are insensitive to concentration while forprofits charge lower interest rates in less concentrated markets. This is consistent with our conceptualization of the differing motivations for for-profit lenders (who charge the highest incentive compatible rate) and non-profit lenders (who charge break-even interest rates). McIntosh and Wydick (2005) study theoretically the effects of competition on lenders' ability to cross-subsidize between clients who vary in their wealth. Baland et al. (2013) also study the choice between JL and IL contracts, focusing on the relationship with borrower wealth and arguing that wealthier borrowers are better served by JL. Our conceptualization of competition closely relates to Shapiro and Stiglitz (1984) and Hoff and Stiglitz (1997).

We do not claim great theoretical novelty for the basic workhorse model in this paper, which we have used in earlier work and which takes its lead from Besley and Coate (1995). The focus of this paper is two positive questions. First, is the anecdotal trend away from joint liability observable in the data? Second, how does it relate to commercialization of the sector? In two prior papers we have used variants of the same model to study different questions. In de Quidt et al. (2016) we abstract completely from market structure, studying an environment with a single non-profit lender, and analyze theoretically when individual liability can mimic features of joint liability. ${ }^{7}$ In de Quidt et al. (in

\footnotetext{
${ }^{7}$ Allen (2016) works with a very similar model, studying structurally the optimal extent of "partial" joint liability.
} 
press) we focus on a normative question: what are the welfare consequences of different market structures. We use a restricted version of the model in this paper to analyze welfare in three equilibria: a monopolist non-profit, monopolist for-profit, and perfect competition. The focus on equilibrium precludes the comparative static analysis on changes to market structure that we need for the questions of interest to this paper.

In a recent related paper, Ahlin and Suandi (2018) empirically study determinants of JL lending, and point to the same time trend away from JL that we identify. They argue that the trend can in part be explained by MFIs reducing the share of JL in their portfolios as they age, which they suggest could be driven by gained experience in overcoming asymmetric information without the use of JL. Because age effects are not identified separately from time effects, they adopt a bounding approach that models the age effect as a step function in age quintiles, as well as a Hausman-Taylor hybrid fixed-effects estimator. Our analysis always controls flexibly for time (absorbing age effects), and therefore provides a complementary explanation.

Existing empirical work comparing IL and JL tends to focus on comparing the impact of credit under different contracts, or the relative performance of the two contract forms on repayment and other outcomes. Giné and Karlan (2014) show that converting joint liability groups to individual liability groups at an MFI in the Philippines did not affect average repayment rates (the average effect is a precisely-estimated zero). Carpena et al. (2013) study a natural experiment in which an Indian MFI switched from using IL to JL, exploiting variation in the switch date determined by the maturity of previous loans. They find a substantial improvement in repayment rates, in line with the model we use in this paper. Mahmud (2015) uses a similar strategy to study the decision by a Pakistan MFI to switch to JL, and again finds positive repayment effects. Attanasio et al. (2015) randomized Mongolian borrowers into either JL, IL or a control (no credit treatment). They find some positive economic impacts of access to JL credit, no significant impacts of IL credit, and no difference in repayment rates. Overall, the evidence seems consistent with JL (weakly) 
improving repayment rates, as it does in our model, though it should be noted that the two randomized studies do not find significant effects.

The paper is organized as follows. Section 2 presents the three stylized facts that motivate the theory. Section 3 presents the model and the theoretical analysis. Section 4 presents the empirical results. Section 5 explores various robustness checks. Section 6 provides a discussion of the role of social capital in the model, and informal discussion of further extensions. Section 7 concludes. Our Web Appendices describe the dataset construction, derivation of theoretical results, and additional tables and figures.

\section{Stylized facts}

In this section we document three simple stylized facts. 1) The share of for-profit MFIs has grown over time, indicating a shift away from non-profit lending; 2) the average number of MFIs operating in each country has grown over time, indicating increasing competitiveness in the sector; 3) the use of joint liability has declined over time. The first two stylized facts relate to our notion of commercialization, as capturing both the shift to for-profit lending and the increase in competition in the sector. The third shows the changing lending methodology that is the main outcome in our analysis. We defer a detailed description of the dataset to section 4.1 and Web A. ${ }^{8}$

After introducing these three facts, we discuss the proxy variables that we use to capture competitiveness in our main empirical analysis. Finally we provide a brief discussion of drivers of changes in commercialization.

\subsection{Stylized fact 1: shift to for-profit lending}

The first stylized fact is reflected in panel (a) of Figure 1, which shows a gradual increase in the fraction of MFIs that lend for profit over the period 1998-2009.

\footnotetext{
${ }^{8}$ We note that our related paper, de Quidt et al. (in press), includes the figures documenting (1) and (2), citing this paper as their source.
} 
To create this figure, we construct a measure of the fraction of MFIs that lend for profit, over time. Our dataset does not contain meaningful entry/exit information during the panel period, but we can reconstruct the past evolution of the microfinance sector by using information on MFI incorporation dates and for-profit/non-profit status. Specifically, we take the universe of MFIs that ever reported to MIX and that report incorporation dates and profit status. ${ }^{9}$ Under the admittedly strong assumption of no changes in profit status and no differential exit by profit status, the incorporation dates allow us to examine how for-profit and non-profit lending have evolved over time.

For each year, we plot the fraction of lenders that were incorporated on that year or before, that are reported as lending for profit. The upward trend we observe implies that for-profit lenders tend to have been incorporated later than non-profits. Based on this measure we would conclude that the industry was initially made up predominantly of non-profit lenders, but subsequent entry has been dominated by for-profits. ${ }^{10}$

\subsection{Stylized fact 2: growth in the number of lenders}

To give a sense of how competitiveness of the microfinance sector has evolved, we next study the evolution of the number of lenders per country, in panel (b) of Figure 1. We take the universe of MFIs that ever reported to MIX and that report founding dates, and use these to construct the number of MFIs founded prior to each given year, finding that the average number of MFIs per

\footnotetext{
${ }^{9}$ See Web Appendix A for details on how these were collected.

${ }^{10}$ There are four potential biases in this figure. First, we cannot observe historical market shares, so we weight each MFI equally. If non-profit MFIs have increased lending significantly faster than for-profits, the true upward trend in for-profit market share would be lower. Second, survivor bias: MFIs that shut down before data collection by MIX will not appear in the data. If for-profits fail more frequently than non-profits, it could be that the true for-profit share has not increased as much as it appears to have done. Third, we do not observe changes in profit status, only the status as of 2011. However, inspecting changes in legal status (e.g. NGO to non-bank financial intermediary) over 2008-2014, we suspect that these are relatively rare compared to new entries, and changes are more likely to be from NGO to other forms that are more likely to be for-profit, we provide further discussion on this below. Finally, we can only include data for MFIs that report to MIX, including their profit status and founding dates. If non-profits and for-profits' report at different rates, and these rates are changing over time, the picture would change. In general, we expect each of these concerns to primarily affect the level of the for-profit share, rather than the qualitative trend.
} 
country roughly doubled over the same period, consistent with our narrative of increasing competition in the industry. ${ }^{11}$

\subsection{Stylized fact 3: decline of joint liability}

The third and final stylized fact is captured in panel (c) of Figure 1, which illustrates the change in MFI lending methodologies over time. This is challenging, because reporting limitations constrain us to examining within-MFI trends. We do the best we can given the data limitations, and find evidence of a trend toward IL in the 2008-2014 period.

For each MFI we compute, for each year it is available, the fraction of IL loans. Not all MFIs report lending method in all years. Therefore looking at cross-sectional means over time risks confounding changes in actual lending practices with selection into and out of the sample. We instead plot only withinMFI changes. In other words, we show the evolution of the average MFI's IL share over time, taking out changes in the composition of that average. We regress IL shares on year and MFI fixed effects, weighting observations by the number of loans, for the $583 \mathrm{MFIs}$ that report lending methodology at least twice in our sample. The graph then plots the year fixed effects. The weighting means that the graph tracks the fraction of all loans made by this sample that were under individual liability, and indicates a roughly 5 percentage point increase in the share of IL loans over the period.

Web Appendix Figure C.4 includes confidence intervals which show that the trend is statistically significant, and explores alternative methods to weight the underlying data. Web Appendix Figure C.5 plots the trend graphs for each possible panel definition in turn, i.e. restricting to MFIs observed at least 2 times, at least 3 times, etc. We lose approximately one sixth of the MFIs at each step, but the basic trend is robustly preserved.

\footnotetext{
${ }^{11}$ As with stylized fact 1 , we do not observe entry or exit during our sample period, but we can again reconstruct historical entry patterns using founding dates. This will tend to understate the number of lenders in operation because we do not observe founding dates for all MFIs, because there may have been lenders operating in the past who shut down before reporting to MIX, and because there may be other lenders currently in operation who do not report to MIX.
} 
We believe this is the most thorough empirical demonstration of the trend away from JL in the literature thus far. Giné and Karlan (2014) also mention the trend. They document the fraction of MFIs in the MIX data that use either individual, group or both types of loans for the years 2007-2009 (whereas we examine portfolio shares). These figures also suggest a trend away from JL, but the time series is short and the data are not adjusted for selective reporting (in 2007 just 31 institutions reported their lending methodology, hence our focus on 2008-2014). Ahlin and Suandi (2018) use the same data that we use and also study this trend. ${ }^{12}$ Their main focus is on how it relates to MFI aging, and they also examine certain macroeconomic predictors of the trend. They do not study market structure or commercialization.

\subsection{Competitiveness proxy measures}

As we discuss further in section 4.1, we do not have sufficient data to construct a measure of microfinance sector competitiveness during the sample period in which we also observe lending methodology (2008-2014), so instead we use a proxy variable approach, based on three variables that are commonly referred to as measures of financial access or financial depth (see e.g. Levine, 2005; Čihák et al., 2013). ${ }^{13}$ These are financial access, measured by a) Commercial Bank Branch density and b) ATM density, and financial depth, measured by c) the ratio of domestic credit provided by the financial sector to GDP. Our primary analyses use the first principal component of these three variables.

We believe that these financial access measures constitute reasonable proxies for competitiveness in our model, in which competition increases borrowers' alternative credit options if they default at their current lender (furthermore, as we argue in Section 3.8, our results extend to other notions of competitiveness).

\footnotetext{
${ }^{12}$ Our main analysis uses data that they kindly shared with us. They estimate time fixed effects in regressions with other controls but do not quantitatively study the trend by itself, in isolation from other regressors, as we do in the figures discussed in this section.

${ }^{13}$ These are available from the World Bank Development Indicators and have been collected mainly through the Financial Access Surveys, maintained by the International Monetary Fund. This data has been used in the past to study outreach of the financial sector, e.g. by Beck (2007) or Ahlin et al. (2011).
} 
For the formal banking sector, Beck et al. (2004) suggests that financial access and depth are positively associated with competition, and Cull et al. (2014) argue using these measures that banks compete with MFIs. To the extent that the formal sector competes with the microcredit sector, they are a direct measure of borrowers' outside options. Additionally, they are expected to capture underlying trends that spur formal sector development and microcredit growth.

Financial access has expanded steadily over time: the number of bank branches per 1 million inhabitants has increased from 9.57 to 18.2 over our sample period. The prevalence of ATMs follows a similar pattern. Financial depth, as measured by domestic credit, has expanded by around $17.3 \%$ over the sample period. We plot these trends in Figure 1 panel (d).

\subsection{What drives commercialization?}

We are not aware of good evidence for, nor do we model why the sector is becoming more commercialized. Our theoretical analysis takes the trends toward a more competitive and for-profit microcredit industry as given and exogenous, while our empirical analysis adopts different fixed-effects strategies with robustness checks to address the most obvious endogeneity concerns (though we do not claim to perfectly address endogeneity).

Cull et al. (2009) discuss the issue, and argue that commercialization may in part reflect a change in the policy environment and donor preferences. They write (p170-171):

In the 1980s and 1990s, policymakers took a big leap, arguing that the new microfinance institutions should be profitable- or in the prevailing code language, they should be "financially sustainable." ... In this spirit, donors encouraged both nonprofit and for-profit microfinance institutions to raise interest rates. Use subsidies sparingly, donors argued, and only in the start-up phase. Earn ample profits and expand as rapidly as profits allow. Commercialize. Attract private investors. 
Our explicit focus is on the observable shift toward competitiveness and for-profit motivation as described in the above quote. While potentially also important, we do not model unobservable shifts in interest-rate setting policies (in our model rates depend only on fundamentals and lender profit motivation) or donor preferences (which might affect operating costs).

A plausible alternative explanation is simply that the industry is in transition to a long-run competitive equilibrium, which began with the entry of (often subsidized) non-profits.

\section{Model}

Our starting point is a model of credit under weak enforcement, as in Besley and Coate (1995). In our model credit is demanded for (risky) investment purposes because this naturally leads to a tractable framework in which the value of credit access stems from the expected discounted value of future output. Given recent evidence suggesting that the representative microcredit borrower does not seem to be engaging in high-return investment activities (see e.g. Banerjee et al., 2015), this may be an unrealistic assumption. However, all that is required for our core mechanism, which stems from a set of incentive compatibility constraints, is that borrowers a) value credit access both today and in the future, b) are tempted to default on their repayment obligations, and c) are sometimes unable to repay their loans, none of which we view as controversial.

There is a population of atomistic, risk neutral borrowers. Each period they have access to a productive technology that requires one unit of capital and produces $R>1$ units of output with probability $p>0$ (success), and nothing otherwise (failure). Borrowers do not have access to a saving technology so must borrow one unit of capital each period if they wish to invest. ${ }^{14}$ Borrowers' liability is limited to their cash on hand, so they cannot repay if unsuccessful.

\footnotetext{
${ }^{14}$ This is a common assumption in the literature, and some form of saving constraint is required to avoid a Bulow and Rogoff (1989) unravelling of the dynamic repayment incentives used by the lender. It does not appear unreasonable in the microcredit context, see e.g. Dupas and Robinson (2013a,b).
} 
They discount exponentially with discount factor $\delta .{ }^{15}$

There are one or more lenders, who each face a gross opportunity cost of funds equal to $\rho$. If the borrower is successful in obtaining a loan, she borrows 1 each period and repays gross interest rate $r$. If she defaults, her contract is terminated and she receives no future loans from that lender. In the equilibria we focus on she will repay with some probability $\pi$ (i.e. paying $\pi r$ in expectation each period), and her contract will be renewed with probability $\pi$. If it is terminated, she becomes "unmatched" and receives continuation value $U$ (e.g. the option value of waiting for a new lender to offer her a contract). The value function of a borrower who has received a loan is therefore

$$
V=p R-\pi r+\delta \pi V+\delta(1-\pi) U=\frac{p R-\pi r}{1-\delta \pi}+\frac{\delta(1-\pi) U}{1-\delta \pi} .
$$

Lenders can offer either IL or JL contracts. An IL contract requires a borrower to repay her loan, otherwise her contract is terminated. She faces one choice: whether to repay when successful. If the contract makes her better off repaying than defaulting, she repays whenever successful, i.e. with probability $\pi^{I L}=p$.

A JL contract binds together a pair of borrowers and requires both loans to be repaid, otherwise both contracts will be terminated. This gives borrowers an incentive to repay on behalf of an unsuccessful partner, an incentive that can be strengthened by the use of social sanctions. ${ }^{16}$ However it might also induce a successful borrower to default rather than repay on behalf of her unsuccessful partner. In the latter case it is straightforward to show that IL can earn both higher profits and higher borrower welfare than JL, so JL will not be offered.

\footnotetext{
${ }^{15}$ The benchmark model assumes the borrower wants to borrow every period, but easily extends to the possibility that with some probability $x$ she discovers at the beginning of the period that she will never want to borrow again (e.g. because she loses access to the investment technology, or because of a positive wealth shock). In this case, her effective discount factor becomes $\delta^{\prime}=\delta(1-x)$ because with probability $x$ the continuation value of the loan contract falls to zero. A similar modification can allow for the case where she only wants to borrow infrequently.

${ }^{16} \mathrm{~A}$ possibility that we do not consider in this paper (because it does not arise in equilibrium under our assumptions) but analyze extensively in de Quidt et al. (2016) is that IL borrowers might also assist one another with repayment.
} 
In the former, both loans are repaid whenever at least one borrower succeeds, with probability $\pi^{J L}=p(2-p) .{ }^{17}$ We define

$$
q \equiv p(2-p)
$$

Borrower welfare under IL and JL therefore equals:

$$
\begin{aligned}
V^{I L} & =\frac{p R-p r}{1-\delta p}+\frac{\delta(1-p) U}{1-\delta p} \\
V^{J L} & =\frac{p R-q r}{1-\delta q}+\frac{\delta(1-q) U}{1-\delta q} .
\end{aligned}
$$

The first incentive constraint, IC1, is identical under IL or JL: the borrower must be willing to repay her own loan (under JL: when her partner is also repaying). If she does, she renews her contract and receives continuation value $V$, if she does not, she becomes unmatched and receives $U$. The condition is thus $\delta V-r \geq \delta U$, which simplifies to:

$$
r \leq \delta p R-\delta(1-\delta) U \equiv r_{I C 1}(U)
$$

Under JL there is a second constraint, IC2: the borrower must be willing and able to repay on behalf of her unsuccessful partner. Her choice is to either repay two loans and renew her contract, receiving $V$, or default. If she defaults, her contract is terminated and she faces a social sanction of size $S$, so she receives $U-S .{ }^{18}$ Thus the condition is $\delta V-2 r \geq \delta(U-S)$, or:

$$
r \leq \frac{\delta p R-\delta(1-\delta) U+\delta(1-\delta q) S}{2-\delta q}=\frac{r_{I C 1}(U)+\delta(1-\delta q) S}{2-\delta q} \equiv r_{I C 2}(U, S) .
$$

Only one of IC1 or IC2 can bind, depending on the level of $S$. IC2 is tighter if $r_{I C 2}(U, S) \leq r_{I C 1}(U)$, or:

$$
S \leq p R-(1-\delta) U \equiv \bar{S}(U)
$$

\footnotetext{
${ }^{17}$ For simplicity, we assume throughout the symmetric equilibrium such that successful borrowers always repay their own loan when their partner was successful, and repay both when their partner was unsuccessful. This maximizes expected borrower welfare and has the weakest incentive compatibility conditions over all (time-invariant) repayment rules.

${ }^{18} \mathrm{An}$ obvious question is why the JL version of IC1 does not include an $S$ term, i.e. why does a JL borrower's partner not sanction her for defaulting? The reason is that under JL, the partner has no reason to threaten a social sanction in this case: if IC1 is violated it is optimal for both borrowers to default.
} 
We take social capital, $S$, to be a measure of all the informal means borrowers can use to persuade one another to assist with repayment. These can include loss of reputation, loss of a friendship, shame, non-pecuniary punishments, et cetera. ${ }^{19}$ We assume that $S$ is symmetric within borrowing groups, is observable to the lender (so the lender can base his contract offer on $S$ ), and distributed in the population with cumulative density $F(S)$. A weaker assumption that would give the same qualitative conclusions would be that the lender bases contracts on observable individual or community-level predictors of $S$.

For IC1 to hold it must be that $V>U$ : alternative sources of credit cannot be so freely available that the borrower is always better off defaulting on her current loan and taking her outside option. We therefore assume there is excess demand for credit (credit rationing), ensuring that a) lenders are free to set the interest rate and b) lenders can always costlessly replace a terminated borrower. $^{20}$

Next, we must check whether the borrower is able to repay, i.e. check the relevant limited liability constraint(s) (LLC). IC1 implies $r<R$, so the borrower can always repay at least one loan. Under JL the borrower must sometimes repay two loans, requiring $2 r<R$. For simplicity we impose a parameter restriction that ensures that the LLC never binds. In equilibrium, IC1 ensures that $r$ can never exceed $\delta p R$, so we assume $\delta p R<\frac{R}{2}$ or:

Assumption 1. $\delta p<\frac{1}{2}$.

In other words, incentive compatibility implies tighter constraints than limited liability. Obviously this is a somewhat restrictive condition: the borrower's income when successful must exceed the full repayment of two loans. We note that our qualitative results do not depend upon this and that the equivalent restriction would become weaker if we allowed for larger borrowing groups (so the repayment burden can be split across more successful partners) or for borrower

\footnotetext{
${ }^{19}$ For further discussion, see de Quidt et al. (2016) and de Quidt et al. (in press).

${ }^{20}$ If the borrower's outside option derives exclusively from access to alternative MFI lenders, credit rationing is guaranteed in equilibrium (de Quidt et al., in press).
} 
output to take intermediate values between 0 and $R$ (such that the unsuccessful partner has some income that can contribute to her repayment, reducing the burden on the successful partner).

Next, to focus on the choice between IL and JL, we assume that the lender is always able to at least break even under an IL contract. In other words we impose a lower bound on the absolute profitability of IL. We define a maximum value for $U, \bar{U}$ such that IC1 just binds at the zero-profit interest rate, i.e. $\operatorname{pr}_{I C 1}(\bar{U})=\rho$.

Assumption 2. $U \leq \bar{U} \equiv \frac{\delta p^{2} R-\rho}{\delta p(1-\delta)}$.

Assumption 2 implies that IC1 is also satisfied under JL at the zero profit JL interest rate: $q r_{I C 1}(\bar{U})>\rho$, since $q>p$, which allows us to focus on IC2 in the analysis below. If $U>\bar{U}$, IL makes a loss. This implies that both lender types will either offer JL, or shut down if JL is also loss-making, so there is no variation in contracts offered. We discuss the effects of relaxing the assumption in section 5.6.

Our final parameter assumption affects the relative profitability of IL and JL. JL is more profitable than IL if the maximum revenue under JL, $q \min \left\{r_{I C 1}(U), r_{I C 2}(U, S)\right\}$ (which is obtained when the tightest constraint binds), is higher than the maximum revenue under IL, which is $\operatorname{pr}_{I C 1}(U)$.

If JL is more profitable than IL (which we have assumed is always profitable) for all values of $S \geq 0$ then (as we show below), lenders will always offer JL. In this case there is little interesting to say about the relationship between commercialization and contract choice. We therefore focus our attention on the more interesting case which obtains when IL is more profitable than JL at $S=0$. In other words, we assume that $\operatorname{pr}_{I C 1}(U)>q r \min \left\{r_{I C 1}(U), r_{I C 2}(U, 0)\right\}$. This condition reduces to:

Assumption 3. $p>\delta q$.

If this assumption does not hold, JL is always offered. The assumption implies that when $S$ is small, IL is the more profitable contract, while for $S$ sufficiently 
large $\mathrm{JL}$ is the more profitable contract. ${ }^{21}$ Therefore Assumption 3 implies there exists a region over which IL is the more profitable and a region over which JL is the more profitable contract.

Assumptions 1 and 3 can be neatly combined in the following condition:

$$
\delta<\min \left\{\frac{1}{2 p}, \frac{1}{2-p}\right\}
$$

Web Appendix Figure C.1 plots the values of $(p, \delta)$ that satisfy this condition.

\subsection{Non-profit lender}

The non-profit chooses the contract that maximizes borrower welfare, subject to IC1, IC2 and a zero-profit condition: $\pi r \geq \rho$, where $\pi$ is the repayment probability. We denote equilibrium values (for example, utilities, interest rates) under non-profit lending with a "hat" (e.g. $\hat{x}$ ). The non-profit interest rates under IL and JL are:

$$
\hat{r}^{I L} \equiv \frac{\rho}{p} \quad \hat{r}^{J L} \equiv \frac{\rho}{q} .
$$

Substituting for $\hat{r}^{I L}$ and $\hat{r}^{J L}$, inspection of (1) and (2) reveals that $\hat{V}^{J L}>$ $\hat{V}^{I L}$. When the JL contract is incentive-compatible, borrowers are able to repay more frequently, lowering their interest rate and increasing their contract renewal probability. Therefore, the lender will always offer JL provided it is profitable at $\hat{r}^{J L}$. This can be written as $\rho \leq q \min \left\{r_{I C 1}(U), r_{I C 2}(U, S)\right\}$. As discussed above, Assumption 2 implies that $\rho \leq q r_{I C 1}(U)$. Therefore we we can focus attention on whether IC2 is satisfied, obtaining a threshold condition:

$$
S \geq \max \left\{0, \frac{(2-\delta q) \rho-\delta q[p R-(1-\delta) U]}{\delta q(1-\delta q)}\right\} \equiv \hat{S}(U) .
$$

If $S<\hat{S}$, IL is offered, if $S \geq \hat{S}$, JL is offered.

It could be that the second term in the maximum is negative, in which case $\hat{S}(U)=0$ and the non-profit offers JL for all values of $S .{ }^{22} \hat{S}(U)=0$ if:

$$
U<\frac{\delta q p R-(2-\delta q) \rho}{\delta q(1-\delta)} \equiv \underline{U}
$$

\footnotetext{
${ }^{21}$ For intuition, note that when $S$ is very large, IC1 becomes the binding constraint under $\mathrm{JL}$, and at this point $\mathrm{JL}$ is strictly more profitable than IL, because $q r_{I C 1}(\bar{U})>p r_{I C 1}(\bar{U})$.

${ }^{22}$ This follows because social sanctions cannot be negative, i.e. $S \geq 0$
} 
A little algebra shows that $\underline{U}=\bar{U}-(p-\delta q) \rho / \delta q(1-\delta)$. Assumption 3 then implies $\underline{U}<\bar{U}$, so there always exists a region $(\underline{U}, \bar{U}]$ over which the non-profit offers IL to borrowers with sufficiently low values of $S$.

Our first result relates the non-profit's use of JL to the level of competition. Increasing competition is captured by an increase in the borrower's outside option, $U$. If she defaults on a loan from her current lender, she can go on to obtain a loan elsewhere. This tightens both IC1 and IC2, since the maximum interest rate at which repayment is incentive compatible under either contract decreases.

Proposition 1. $\hat{S}^{\prime}(U) \geq 0$, with the inequality strict for all $U>\underline{U}$. In other words, the minimum amount of social capital needed for joint liability to break even is (weakly) increasing in the level of competition. Thus, competition (weakly) increases individual liability lending by non-profits.

Competition improves the borrower's outside option, reducing the cost of losing her existing contract. As a result, for a given interest rate the minimum level of social capital for a borrower to be willing to repay her partner's loan is increasing in competition.

\subsection{For-profit lender}

The for-profit lender, unsurprisingly, maximizes profits. We denote equilibrium quantities under for-profit lending by a tilde $(\tilde{x})$. Since he can always costlessly replace a terminated borrower next period, he does not discount future profits from a given borrower, instead maximizing only per-period profit $\Pi=\pi \tilde{r}-\rho$, and since costs are assumed to be the same under both contracts he merely compares revenues $\pi \tilde{r}$ when choosing which contract to offer. Profits are maximized at the maximum incentive-compatible interest rate, which under IL is $\tilde{r}^{I L}(U)=r_{I C 1}(U)$. Under JL the maximum rate is the minimum of $r_{I C 1}(U)$ and $r_{I C 2}(U, S)$, so $\tilde{r}^{J L}(U, S)=\min \left\{r_{I C 1}(U), r_{I C 2}(U, S)\right\} .^{23}$

\footnotetext{
${ }^{23}$ If the lender sets the JL interest rate higher than $r_{I C 2}(U, S)$, then the borrowers repay only when both are successful, with probability $p^{2}$, and he cannot earn more than under IL. If he sets $r>r_{I C 1}(U, S)$ the borrowers always default.
} 
The lender offers JL when $q \tilde{r}^{J L}(U, S) \geq p \tilde{r}^{I L}(U)$, or:

$$
S \geq \frac{p(p-\delta q)[p R-(1-\delta) U]}{q(1-\delta q)} \equiv \tilde{S}(U) .
$$

It is easy to check that $\tilde{S}(U) \geq \hat{S}(U)$, with the relation holding strictly when $U<\bar{U} \cdot{ }^{24}$ Hence the for-profit is more likely to offer IL than the non-profit.

Proposition 2. For a given level of competition, $U<\bar{U}$, a for-profit lender is more likely to offer individual liability than a non-profit: $\tilde{S}(U)>\hat{S}(U)$.

The intuition for the proposition is straightforward. The non-profit offers JL whenever it breaks even, because JL maximizes borrower welfare. The for-profit also requires JL to break even, but additionally it must be more profitable than IL. Since this is a stricter condition, the for-profit ends up offering JL to fewer borrowers.

We have assumed that the for-profit is myopic, ignoring the impact on future profits of retaining a borrower for longer. The motivation for this assumption is that lenders have limited capacity relative to demand, so the lender can easily replace a defaulting borrower next period. However, it is easy to see that the result also holds for a patient for-profit, who discounts the future with discount factor $\beta \in[0,1]$. Now the net present value of profits from a given borrower are $\frac{\pi \tilde{r}-\rho}{1-\beta \pi}$. The non-profit offers JL provided it is possible to break even with a JL contract, which is equivalent to checking $q \tilde{r}^{J L}(U, S)-\rho \geq 0$. The for-profit offers $\mathrm{JL}$ whenever it is more profitable than IL, i.e. when $\frac{q \tilde{r}^{J L}(U, S)-\rho}{1-\beta q} \geq \frac{p \tilde{r}^{I L}(U)-\rho}{1-\beta p}$, which is a more restrictive condition for all $\beta$ as $\frac{p \tilde{r}^{I L}(U)-\rho}{1-\beta p} \geq 0$.

Next we consider the impact of competition on the for-profit's use of JL.

Proposition 3. $\tilde{S}^{\prime}(U)<0$. In other words, the minimum amount of social capital needed for joint liability to be more profitable than individual liability is decreasing in the level of competition. Thus, competition decreases individual liability lending by for-profits.

\footnotetext{
${ }^{24}$ The expressions for $\hat{S}$ and $\tilde{S}$ coincide at $U=\bar{U}$, i.e. when $U$ is so high that IL is just breaking even.
} 
The result follows from the fact that revenue under $\mathrm{JL}$ is less sensitive to $U$ than under IL. Under IL the relevant incentive constraint (IC1) determines the maximum single payment the borrower is willing to make, $\delta(V-U)=r$, so increases in $U$ are passed through to decreases in $r$. Under JL, the relevant incentive constraint (IC2) determines the maximum double payment the borrower will make, $\delta(V-U+S)=2 r$, so for a given decrease in the left-hand-side, the interest rate $r$ falls by half as much. ${ }^{25}$ Therefore, profits decrease faster under IL than JL, which can make JL more profitable when $U$ is sufficiently high.

Collecting results, we see that competition decreases JL usage by non-profits. Conversion to for-profit also decreases JL usage, but competition increases JL usage by for-profits. Finally, an observation:

Observation 1. For a given level of social capital, $S$, an increase in $U$ cannot induce both the non-profit to switch from joint liability to individual liability and the for-profit to switch from individual liability to joint liability.

The observation follows formally from Proposition 2, which shows that for profits always have a higher threshold than non-profits for offering JL. Intuitively, if the non-profit switches to IL it is because JL can no longer break even, thus the for-profit will not switch to JL.

\subsection{Summary and graphical representation}

In this section we provide a short summary of our predictions for lenders' contract choice, and a graphical representation of the findings.

Non-profit lenders are assumed to offer the contract that maximizes borrower welfare, provided they can break even doing so. Our model predicts that JL is preferred by borrowers due to its insurance properties, so the lender offers JL at the zero-profit interest rate when this satisfies IC1 and IC2, and otherwise offers IL. Importantly, unlike the for-profit, the non-profit will offer JL even if

\footnotetext{
${ }^{25}$ Note that $V$ also depends on both $U$ and $r$, with different slopes under IL and JL, complicating the relation between $U$ and $r$. Inspection of $r_{I C 1}$ and $r_{I C 2}$ reveals that $\frac{\frac{d r_{I C 2}(U, U)}{d U}}{\frac{d r_{I C 1}(U)}{d U}}=\frac{1}{2-\delta q} \in(0.5,1)$.
} 
IL earns higher profits. For-profit lenders offer whichever contract maximizes profits, irrespective of borrower welfare. Thus their decision depends on the relative tightness of IC1 under IL to IC1 and IC2 under JL.

Under our Assumption 2, IC1 is always satisfied under IL and JL. Additionally $\mathrm{JL}$ is more profitable than IL if IC1 is binding, since the repayment rate is higher under JL. That enables us to summarize the lenders' choices simply, in table 1 .

\begin{tabular}{|c|c|c|}
\hline & Individual liability & Joint liability \\
\hline \multicolumn{3}{|l|}{ Non-profit } \\
\hline $\begin{array}{l}\text { Interest rate } \\
\text { Contract offered if }\end{array}$ & $\begin{array}{c}\hat{r}^{I L}=\frac{\rho}{p} \\
\hat{r}^{J L}>r_{I C 2}(U, S)\end{array}$ & $\begin{array}{c}\hat{r}^{J L}=\frac{\rho}{q} \\
\hat{r}^{J L} \leq r_{I C 2}(U, S)\end{array}$ \\
\hline \multicolumn{3}{|l|}{ For-profit } \\
\hline $\begin{array}{l}\text { Interest rate } \\
\text { Contract offered if }\end{array}$ & $\begin{array}{c}\tilde{r}^{I L}=r_{I C 1}(U) \\
p \tilde{r}^{I L}>q \tilde{r}^{J L}\end{array}$ & $\begin{array}{c}\tilde{r}^{J L}=\min \left\{r_{I C 1}(U), r_{I C 2}(U, S)\right\} \\
p \tilde{r}^{I L} \leq q \tilde{r}^{J L}\end{array}$ \\
\hline
\end{tabular}

Table 1: Lender's contract choice and interest rate

Figure 2 shows the combinations of contracts offered by non-profit and forprofit lenders for different combinations of $U$ and $S$. For clarity, we first plot the regions separately for the two lender types, then combine them on a single plot. The graphs plot the two functions, $\hat{S}$ and $\tilde{S}$, the threshold $\bar{U}$ implied by Assumption 2, and shade the regions corresponding to different contract combinations. ${ }^{26}$

Assumption 2 restricts $U$ to the region where IL is always profitable, which is bounded by $\bar{U}$. The plots also include the region $U>\bar{U}$ where IL is loss-making but JL is not for sufficiently high $S$, in which case both lender types offer JL. We discuss the relaxation of Assumption 2 below, in section 3.6.

The figures show clearly the three key parameter regions identified by the theory: a region with low $S$ where both lenders offer IL, a region with inter-

\footnotetext{
${ }^{26}$ The graphs can also be interpreted as plotting the incentive constraints IC1 and IC2, where they coincide with zero profits. Specifically, $\bar{U}$ plots the level of $U$ such that $\operatorname{pr}_{I C 1}=\rho$, i.e. IL earns zero profits. $\hat{S}(U)$ plots the values of $S$ and $U$ where IC2 is tighter than IC1 and JL earns zero profits, i.e. $q r_{I C 2}(U, S)=\rho$.
} 
mediate $S$ where for-profits offer IL and non-profits offer JL, and a region with high $S$ where both offer JL. In the additional region introduced by relaxing Assumption 2, where both $S$ and $U$ are large, both lenders also offer JL.

Web Appendix figure C.2 shows how the contract regions change as we vary the model parameters $\rho, R, \delta$ and $p$.

In typical models a non-profit is indistinguishable from the limit case of a for-profit that is operating in a competitive equilibrium. ${ }^{27}$ Interestingly this is not the case in our model. We analyze how lenders respond to changes in the competitive environment, and therefore necessarily are studying behavior out of competitive equilibrium. The contract offered by a non-profit in this setting can be different from what a for-profit would do, were it in competitive equilibrium. This is easiest to see by inspecting Figure 2. Take for instance the case where $S$ and $U$ are initially equal to zero. The non-profit would choose to offer JL in such a setting. However, as $U$ increases due to entry, we cross the $\hat{S}$ line (JL ceases to be feasible). In other words, when $S$ is low, the non-profit will offer JL if $U$ is also sufficiently low, while a competitive non-profit will never offer JL. We provide further discussion of competitive equilibrium in Section 3.7.

\subsection{Joint liability over time}

Now we use the assumed heterogeneity of $S$ in the population to study changes in the aggregate level of IL and JL lending. We first derive the steady state share of borrowers receiving IL loans for a given share of for-profit lenders in the market, which we denote by $f$, and a given level of the borrowers' outside option $U$. Then we analyze comparative statics on these variables. We treat $f$ and $U$ as exogenous and independently varying since these are the commercialization variables that we study in the data, and we do not observe in the data an underlying factor that can be argued to cause both.

We assume that lenders are atomistic with a fixed capacity of two borrowers per period, enabling them to each serve either two IL borrowers or one JL group.

\footnotetext{
${ }^{27}$ We thank the editor and an anonymous referee for prompting us to explore this comparison
} 
At the end of each period, lenders terminate all defaulting IL borrowers or JL groups. We then make two technical assumptions for simplicity. First, because IL defaults can leave lenders with a single vacancy, we assume that surviving IL borrowers are reshuffled to fill vacancies in other equivalent IL branches. This ensures that (with the exception of a zero measure of "remainder" borrowers when there is an odd number of defaults) branches either have two or zero vacancies at the beginning of the next period, and can therefore freely offer IL or JL. Second, a borrower whose contract is terminated rejoins the pool of unmatched borrowers and draws a new potential borrowing partner and value of $S$ from $F$. This ensures that $S$ is always distributed according to $F$ in the pool. Atomistic lenders imply that borrowers' histories do not matter since they will never re-match with a previous lender.

Borrowers without a current loan contract receive utility $U$. At the beginning of a period, branches with vacant spaces fill them by drawing a pair of borrowers at random from the pool of unmatched borrowers. They observe the pair's value of $S$, and offer them either an IL or JL contract which determines their value for $V$. Non-profits offer IL when $S<\hat{S}(U)$, i.e. with probability $F(\hat{S}(U))$, and forprofits offer IL when $S<\tilde{S}(U)$, with probability $F(\tilde{S}(U))$. If a borrower rejects, she goes back to the pool until next period. Since the lender will always offer a contract such that $V>U$ (otherwise the incentive conditions are violated), borrowers always accept.

Denote by $\hat{\eta}(U)(\tilde{\eta}(U))$ the steady-state fraction of non-profit (for-profit) lenders offering IL. When filling a vacancy at a non-profit (for-profit) lender, a borrower receives an IL contract with probability $F(\hat{S}(U))(F(\tilde{S}(U)))$, since we assumed she her value of $S$ was drawn anew from $F$. However, IL and JL borrowers default and re-enter the pool at different rates $(1-p$, and $1-q$ respectively), so JL groups survive for longer. As a result in steady state, where the flows into and out of IL/JL are equalized, the fraction of IL borrowers will be smaller than $F(S)$ and the fraction of JL borrowers larger than $1-F(S)$.

Solving for the steady states, we obtain $\hat{\eta}(U)=\frac{F(\hat{S}(U))(1-p)}{1-F(\hat{S}(U)) p}<F(\hat{S}(U))$ and 
$\tilde{\eta}(U)=\frac{F(\tilde{S}(U))(1-p)}{1-F(\tilde{S}(U)) p}<F(\tilde{S}(U))$. The steady state JL shares are $1-\hat{\eta}(U)=$ $\frac{1-F(\hat{S}(U))}{1-F(\hat{S}(U)) p}$ and $1-\tilde{\eta}(U)=\frac{1-F(\tilde{S}(U))}{1-F(\tilde{S}(U)) p}$. Derivations are given in the Appendix.

With these objects in hand, the steady state IL share in the market is $\eta(U)=$ $f \tilde{\eta}(U)+(1-f) \hat{\eta}(U)$. How does the IL share change over time? It depends on the change in $U$ and the change in $f$. We can write it as:

$$
\begin{aligned}
\frac{d \eta}{d t} & =\frac{d f}{d t} \underbrace{[\tilde{\eta}(U)-\hat{\eta}(U)]}_{\geq 0} \\
& +\frac{d U}{d t}(1-p)[f \underbrace{\frac{F^{\prime}(\tilde{S}(U)) \tilde{S}^{\prime}(U)}{(1-p F(\tilde{S}(U)))^{2}}}_{\leq 0}+(1-f) \underbrace{\frac{F^{\prime}(\hat{S}(U)) \hat{S}^{\prime}(U)}{(1-p F(\hat{S}(U)))^{2}}}_{\geq 0}] .
\end{aligned}
$$

An increase in the share of for-profits increases the share of IL lending, as for-profits demand more social capital to offer JL. The effect of an increase in the borrowers' outside option (for example, because of an increase in competitiveness) is ambiguous, as it increases IL lending by non-profits and JL lending by for-profits. However when the initial share of for-profits is low ( $f$ close to zero), the effect of increasing $U$ will also be to increase $\eta$.

Observation 2. Provided the initial share of for-profits in the market is sufficiently low, concurrent growth in for-profit lending and competition lead to an overall increase in IL lending.

\subsection{Other sources of heterogeneity}

In our analysis so far we have allowed $S$ to vary but held other model parameters fixed. In this section we discuss two other dimensions: variation in the cost of capital, $\rho$, across lenders, and variation in the return to capital, $R$, since for both we can derive analytic cutoffs for lenders to offer JL contracts. We propose an empirical test based on the results for $\rho$, which is in principle observable in our data, and we also perform our main analysis controlling for GDP per capita, which may at least partly reflect differences in returns to capital.

We do not formally analyze variation in $\delta$ and $p$, which do not yield interpretable analytic expressions (and which are anyway not observable in the 
data). However, Web Appendix Figure C.2 shows how changes to the model parameters shift the regions over which different contract combinations are offered.

\subsubsection{Variation in $\rho$}

The non-profit lender offers JL whenever JL breaks even, and otherwise switches to IL (which is assumed to be profitable by Assumption 2). The analogous condition to $(7)$ is:

$$
\rho \leq q \frac{\delta p R-\delta(1-\delta) U+\delta(1-\delta q) S}{2-\delta q}
$$

The for-profit lender offers whichever contract earns the highest per-period revenue. As a result, the cost of capital does not enter into their decision about which loan type to offer.

In sum, the cost of capital is not predicted to affect the contract choice of for-profits, but higher-cost non-profits are more likely to offer IL. This has two implications. First, if changes in the cost of capital are associated with changes in commercialization (or our proxy variables), we might misattribute cost of capital affects to commercialization. Second, if non-profits have different operating costs than for-profits, the level difference in usage of IL may partly reflect differences in costs. ${ }^{28}$

The robustness check described in Section 5.3 adds measures of lenders' costs to our main regressions. We do not see much in the way of a systematic relationship with lending methodology, and the results are quite noisy. However, encouragingly, the main commercialization effects are robust to including these measures, suggesting their omission is not an important confound.

\subsubsection{Variation in $R$}

Increases in borrower income upon success, $R$, affect the amount of interest borrowers are willing to repay under both contracts, relaxing IC1 and IC2. This

\footnotetext{
${ }^{28}$ Indeed, in our sample, the cost variables we use are weakly negatively correlated with non-profit status. This would tend to increase JL usage by non-profits, relative to for-profits, potentially reinforcing our results.
} 
makes both contracts more profitable, and hence JL more feasible. Therefore increases in $R$ increase JL lending by non-profits. To see this, we rearrange (7), finding that $\mathrm{JL}$ is offered provided:

$$
R \geq \frac{2-\delta q}{\delta p q} \rho+\frac{(1-\delta)}{p} U-\frac{(1-\delta q)}{p} S
$$

The maximum repayable interest rate under JL, determined by IC2, is less sensitive to $R$ than the interest rate under IL. This is because a borrower has to be willing to repay two loans under JL, so requires larger compensating increases in the return to capital for a given increase in the interest rate. To see this, we rearrange (8). We find that the for-profit offers JL if:

$$
R \leq \frac{(2-p)(1-\delta q)}{p(p-\delta q)} S+\frac{(1-\delta)}{p} U
$$

Higher values of $R$ increase the likelihood the lender switches to IL.

One implication of this is that if, as argued by Cull et al. (2009), nonprofits tend to serve poorer borrowers (which may be partially captured by lower returns to investment), this will tend to reduce their ability to offer JL. As a result, we might underestimate what would be the difference in usage of JL between non-profits and for-profits for comparable borrowers. However, the qualitative comparative static effect of changes in $U$ does not depend on this level difference. While we do not observe borrower incomes directly, one of our empirical robustness checks includes GDP per capita, interacted with the lender's profit status. Encouragingly, our main results are robust to including these controls.

\subsection{Relaxing restrictions on the size of $U$}

Assumption 2 imposes an upper bound on $U, \bar{U}$, that ensures that IL is always profitable and therefore restricts the lenders' choice to a decision between offering IL and JL contracts, simplifying the analysis. In this section we relax the assumption, allowing $U$ to exceed $\bar{U}$.

When $U>\bar{U}$ the lender's options are to offer JL or to shut down. Lenders can offer JL without making a loss provided revenue at the tighter of IC1 and 
IC2 exceeds the cost of capital. IC1 is satisfied provided $\rho<q r_{I C 1}(U)$, which reduces to:

$$
U \leq \frac{\delta p q R-\rho}{\delta q(1-\delta)} \equiv \overline{\bar{U}}
$$

while IC2 is satisfied provided $S \geq \hat{S}(U)$ as before. In sum, when $U \in(\bar{U}, \overline{\bar{U}}]$, both lenders offer JL when $S \geq \hat{S}(U)$, and otherwise shut down. When $U>\overline{\bar{U}}$ both lenders shut down.

What are the implications for contract offerings? Consider first an environment where $U$ is increasing and $S$ is fixed. The reader may find it helpful for intuition to consult Figure 2.

For the non-profit there are two cases. If $S \geq \hat{S}(\bar{U})$ then the lender offers JL for all $U$ until it makes a loss, i.e. for all $U \leq \min \left\{\hat{S}^{-1}(S), \overline{\bar{U}}\right\}$ (i.e. until the tighter of IC1 and IC2 is violated). If $S<\hat{S}(\bar{U})$ then everything goes through as in the prior analysis, and the lender shuts down at $U=\bar{U}$. In other words the predicted monotonicity of contract offerings is preserved - either the lender always offers JL, they offer JL for low $U$ and IL for high $U$, or they always offer IL.

For the for-profit there are three cases. First, if $S \leq \hat{S}(\bar{U})^{29}$ (i.e., if JL is loss making at $\bar{U}$ ) the lender offers IL for all $U \leq \bar{U}$ and shuts down at $\bar{U}$. Second, if $S>\tilde{S}(0)$, i.e. if JL is always more profitable than IL, the lender offers JL for all $U$ until it makes a loss, i.e. for all $U \leq \min \left\{\hat{S}^{-1}(S), \overline{\bar{U}}\right\}$. Finally, in the intermediate case $S \in[\hat{S}(\bar{U}), \tilde{S}(0))$, IL is initially more profitable and the lender switches to JL at $U=\tilde{S}^{-1}(S)$. It then continues to offer JL until JL makes a loss, i.e. for all $U \leq \min \left\{\hat{S}^{-1}(S), \overline{\bar{U}}\right\}$. Once again, the monotonicity of the prior analysis is preserved: either the lender always offers IL, always JL, or initially IL, switching to JL for high $U$.

We summarize the above in the following proposition:

Proposition 4. For homogenous $S$ in the population, individual liability usage is weakly increasing in $U$ for non-profits, and weakly decreasing for for-profits.

\footnotetext{
${ }^{29}$ Note that in Figure 2 the $\hat{S}$ function is labeled "JL zero profits."
} 
The more nuanced case is where a given lender serves heterogenous borrowers, which is likely the case in our data. For example, the lender may have some branches in low $S$ locations and others in high $S$ locations. How does the lender's share of JL contracts evolve as competition increases? Again we refer the reader to Figure 2 for intuition.

The for-profit case is simple. The lender's general tendency to increase the use of JL as $U$ increases is reinforced by the fact that IL lending shuts down altogether at a lower value of $U$ than JL lending. However for the non-profit lender, the portfolio share of JL may evolve non-monotonically as $U$ increases. This is because there is a general tendency for IL usage to increase as $U$ increases (Proposition 4), but at $U=\bar{U}$ then IL lending shuts down altogether, i.e. the portfolio share of IL drops to zero. So we might observe IL shares increasing in competition up to a critical level, before dropping to zero. We summarize these findings in the following proposition:

Proposition 5. For heterogenous $S$ in the population, individual liability usage remains weakly decreasing in $U$ for for-profits. For non-profits individual liability usage is weakly increasing in $U$, before decreasing discontinuously to zero at $U=\bar{U}$.

However, it is less clear that we would expect to observe such a relationship in equilibrium. The argument for IL lending to shut down requires competition for these borrowers to be sufficiently intense (i.e., their outside option is sufficiently good) that no lender can profitably lend to them. This is unlikely to be an equilibrium. Because we are interested in changes in competitiveness in this paper, deriving the full competitive equilibrium is beyond the scope of our analysis, but we provide some discussion in the next section.

In sum, our empirical prediction for the relationship between competition and IL usage is preserved for for-profit lenders, but is potentially non-monotone for non-profits. Therefore in our empirical work we perform a robustness check in which we include only lenders that offered at least some individual liability loans, from which we infer that $U \leq \bar{U}$ in the locations in which these lenders 
operate.

\subsection{Endogenizing $U$}

Ideally, we would like to endogenize $U$ as a function of the scale of lending relative to the borrower population (since this determines how long an unmatched borrower must wait for a loan) and the share of for-profits (since for-profits charge higher interest rates and so are a less attractive outside option). It is straightforward to do so in competitive equilibrium with homogeneous $S$, i.e. when $F$ is degenerate, and we do so in de Quidt et al. (in press) in order to make statements about aggregate welfare. When $S$ is homogeneous a given lender type (non-profit/for-profit) either offers only IL or JL loans. In competitive equilibrium the lender's motivation does not matter: except for knife-edge cases there is just one feasible contract that breaks even. We show that the level of social capital required for the competitive market to offer JL is higher than a monopolist non-profit, and lower than a monopolist for-profit. In other words, transition from an uncompetitive, not-for-profit industry to a competitive one increases the likelihood that IL is used.

However, the model in this paper necessarily focuses on behavior out of competitive equilibrium, to analyze the effect of changing lender motivation and market competitiveness on the contracts offered. Solving for the equilibrium value of $U$ and deriving comparative statics is much more complex in this setting. For this reason, we use our "reduced form" analysis which takes $U$ as given to motivate the below empirical work, in which we test the model's three main predictions: that for-profits are more likely to use IL, that increasing competitiveness increases IL use by non-profits, and decreases it by for-profits. Appendix B.2 outlines how to derive the equilibrium value of $U$ when $U$ is assumed to capture only the possibility of obtaining a loan from a competitor lender in future, and shows (in a restricted case) that $U$ is increasing in the number of lenders in the market. 


\subsection{Ex-ante competition}

So far we have modeled the effects of competition only through the borrower's outside option upon default, i.e. competition is ex-post, only affecting behavior after the contract is accepted. This is natural because we assumed throughout that credit is scarce relative to the number of potential borrowers, such that lenders have market power in setting prices but must pay attention to borrowers' ex-post incentive to repay. However the model does allow us to think in a simple way about ex-ante competition, whereby increased competition constrains the prices lenders can charge or face losing their clients.

There are three natural ways to model ex-ante competition. The first is that competition acts as a simple cap on the interest rate that lenders can charge under either contract, $r \leq \bar{r}$. This has no effect on the contract offering of non-profits, but may cause them to shut down entirely, while it predicts that for-profits increase their use of JL, as in Proposition 3. Non-profits already earn zero profits, so if the cap is binding they must shut down. ${ }^{30}$ For-profits offer the profit maximizing contract, and charge higher interest rates under IL than JL. Therefore, the cap binds first on IL, reducing its profitability and increasing the attractiveness of JL. If it binds on both contracts, the lender will offer JL for sure since the interest rates are equalized but the repayment rate is higher under JL.

Second, ex-ante competition might manifest as a floor on borrower welfare that the contract must meet or exceed. Call this value $\underline{V}$. Since the non-profit maximizes borrower welfare, once again this constraint either has no effect or puts it out of business. Turning to the for-profits, we require $\tilde{V}^{I L} \geq \underline{V}$ and $\tilde{V}^{J L} \geq \underline{V}$. Using expressions (1) and (2), and setting $\tilde{V}^{I L}=\tilde{V}^{J L}=\underline{V}$ (i.e., the constraint binds), we obtain the implied upper bounds on revenue under IL and

\footnotetext{
${ }^{30}$ Notably, the cap doesn't induce switching between contract types. If they were offering IL before the cap we know that JL is not profitable, while because IL rates are higher, if the cap is binding on JL it already rendered IL unprofitable.
} 
JL:

$$
\begin{aligned}
& \overline{\text { Revenue }}^{I L}=p r^{I L}=p R+\delta(1-p) U-(1-\delta p) \underline{V} \\
& \overline{\text { Revenue }}^{J L}=q r^{J L}=p R+\delta(1-q) U-(1-\delta q) \underline{V} .
\end{aligned}
$$

Taking the difference, we obtain $\overline{\text { Revenue }}^{J L}-\overline{\text { Revenue }}^{I L}=\delta p(1-p)(\underline{V}-U)$. Noting that IC1 requires $V>U$, so the constraint can only bind when $\underline{V}>U$, we learn that the constraint is tighter on IL revenue than JL revenue, and therefore, to the extent that it is binding, will also push the lender toward offering JL, again in line with Proposition 3.

Finally, we could conceptualize ex-ante competition as putting an upper bound on profits, i.e. $\Pi=\pi r-\rho \leq \bar{\Pi}$. Assuming $\bar{\Pi} \geq 0$, for the non-profit this is never binding, since it earns zero profits, so once again there is no effect. For the for-profit it either has no effect or makes it indifferent between the contracts. It maximizes profits, $\pi r-\rho$, so this constraint only affects the profitability of the most profitable contract, not their (strict) ordering.

We sum up the findings with the following observation:

Observation 3. Ex-ante competition that increases with commercialization weakly reinforces the qualitative predictions of our main theory. The non-profit's contract choices are unaffected, while the for-profit is either unaffected or increases his use of JL in line with Proposition 3.

\section{Empirical analysis}

\subsection{Data}

The dataset we work with come from MIXMarket.org (henceforth MIX), an organization that collects, validates and publishes financial performance data of MFIs around the world. The MIX is the largest and most comprehensive source of data on microfinance institutions. For example, in 2011, 1,598 MFIs reported data on loan portfolio value and loans outstanding to the MIX. Their combined gross loan portfolio had a value of USD 91.6 billion across 154 million loans. 
Our main estimating sample contains financial data for 548 MFIs across a total of 2,573 observations in the period 2008-2014. This comprises approximately one quarter of the 2,211 MFIs and 8,520 total observations reported to the MIX in this seven year period. ${ }^{31}$ We also replicate our results in an alternate sample that contains 874 MFIs but only years 2008-2011. We describe the construction of the datasets in Web Appendix A.

Our focus in this paper is to highlight trends in lending methodology. The MIX is the only data source of which we are aware that has collected this data systematically over time. Lending methodology, according to the MIX, is categorized into three categories: Individual, Solidarity Group and Village Banking/Self Help Group. We treat Individual loans as IL and Solidarity Group and village banking/self help groups as JL. ${ }^{32}$ Using these data we construct MFI-level IL portfolio shares, "IL shares."

Lending methodology information is provided by MFIs in the Gross Loan Portfolio report (measured by value) and/or in the Number of Loans Outstanding report. In the paper we mostly focus on regressions based on the fraction of the number of loans made under IL, since this is the only measure available in the longer panel we focus on. Our shorter, wider panel does contain the valuebased measure and we show that our results are robust to using this measure. In a world of homogeneous borrowers or atomistic lenders (as in the benchmark model), a given lender's IL share would be either zero or one. When lenders face heterogeneous borrowers, for instance because they have some branches in

\footnotetext{
${ }^{31}$ This dataset relies on data kindly provided to us by Chris Ahlin.

${ }^{32}$ The MIX is not explicit about whether joint liability is used; its definition reads "Solidarity Group lending refers to the use of groups for disbursement of funds and collection of repayment on loans to either the group as a whole or to the individual members of that group. Borrowers of such groups often bear joint and several liability for the repayment of all loans to the group and its members. This group liability may also determine credit decisions made by the institution. Solidarity Groups vary in the degrees to which they use groups for credit decisions, disbursement, collection, or to reduce credit risk. For this standard, loans are considered to be of the Solidarity Group methodology when some aspect of loan consideration depends on the group, including credit analysis, liability, guarantee, collateral, and loan size and conditions.". Other authors taking a similar classification approach to us include Cull et al. (2007; 2014) and Mersland and Øystein Strøm (2009). To the extent that some of these loans are not true JL, we must make the identifying assumption that changes in IL shares reflect true changes in methodology, and not classification.
} 
locations with high $S$ and some with low $S$, their aggregate portfolio will contain a mixture of IL and JL loans.

The main weakness of the MIX data is selection: the MFIs who report methodology data may not be representative of the population of MFIs, either because of missing observations (an MFI does not report in a given year) or missing variables (the MFI does not report one of our key measures in a given year). Because of these concerns, we work throughout with different sources of "within" variation (within region, country, MFI), based on two panel sampling frames. We study a "fully balanced" panel of 111 MFIs, which report lending method by number of loans for all seven years, and a "weakly balanced" panel of 548 MFIs, who report lending methodology by number of loans at least twice.

In view of selection concerns, we note that the MFIs that report lending methodology comprise a reasonable share of all loans in the MIX market dataset. The weakly balanced panels accounts for around $30 \%$ of the value of all loans outstanding across our sample period (the 111 institutions that we observe in every year are of course more selected, making up around $5 \%$ of the total value). We are able to check whether our two panel definitions appear representative of the full set of MFIs that reported to MIX. Table 2 presents summary statistics for the full sample, the weakly balanced and the strongly balanced sample. ${ }^{33}$ We perform t-tests to compare the means of key observables between the MFIs included in each panel and those excluded. Overall the two panel definitions look fairly representative of the full dataset, in particular on our key IL share and profit status variables, though we do find significant differences in some other variables.

For-profit/non-profit status ("profit status") is recorded as a static variable. One concern might be that MFIs have changed profit status over time without us knowing. We do have data on transitions of legal status up to 2011. Legal status and profit status are very tightly related. Most (88 percent) non-profit

\footnotetext{
${ }^{33}$ Because not every MFI is observed every year, we report the 2009 values where available (since 2009 has the greatest data availability), otherwise we take the closest available datapoint (averaging 2008 and 2010 when both are available).
} 
MFIs have either Credit Union/Cooperative or NGO as legal status (see Web Appendix Table C.1). Given the tight correlation between profit status and legal status, and given that a robustness check that removes institutions that changed legal status does not change our results, we think that unobserved changes in profit status are unlikely to endanger our results.

A conventional approach to measuring competition would be to construct market-level concentration indices. This is the approach taken by Baquero et al. (forthcoming), who use proprietary rating agency data to construct Herfindahl indices, studying the effect of concentration on interest rates in the microcredit sector. It is unfortunately not possible, given the incomplete reporting to MIX, to construct plausible concentration measures using our data. We have argued above that our weakly and strongly balanced panels are reasonably representative of the typical MFI in the full sample. We construct portfolio shares at the MFI level based on the relative size of the MFI's reported IL and JL portfolios. We then use fixed effects to isolate plausibly exogenous sources of variation (in the limit, within-MFI variation) to address remaining selection concerns, so as to understand how the lending methodology of a typical MFI relates to commercialization. But to construct plausible country-level concentration measures we would need to observe a stable and representative sample of MFIs at the country level, and then use the variation between MFIs in portfolio size to measure concentration. The amount of selection in and out of the sample due to reporting on a given year makes it difficult to do this plausibly. ${ }^{34}$

We use three proxies for the extent of credit market competition, which enters the borrowers' outside option, $U$, in the model. Our proxies are the number of commercial bank branches per million people, the number of ATMs per million people, and the value of domestic credit provided by the financial sector as a share of GDP. These data come from the Financial Access Survey collected by the International Monetary Fund. They have been used in the past

\footnotetext{
${ }^{34}$ Ideally we would also want to observe entry and exit, but in our data, the latest founding date is 2009 and we cannot distinguish an MFI that exits the market from one that simply ceases to report to MIX.
} 
to study outreach of the financial sector, for example, by Beck (2007), Ahlin et al. (2011), Levine (2005), and Čihák et al. (2013), and are incorporated in the World Development Indicators. In most of our regressions we use the first principal component of these three indicators, standardized to mean zero, standard deviation one, to proxy for credit market competition (details are given in the Appendix). We also perform our analysis for each indicator separately. These and other country-level observables are summarized in Table 3.

\subsection{Empirical Specification}

We test three predictions of the model, that (1) non-profits use JL relatively more than for-profits; (2) that competition increases JL use by for-profits; and (3) competition decreases JL use by non-profits.

To test these predictions, we estimate the following main specification:

$$
I L_{i c r t}=\alpha N P_{i}+\eta C_{c t}+\gamma N P_{i} \times C_{c t}+\mathbf{X}_{i c t}^{\prime} \beta+a_{i c r}+b_{t}+\epsilon_{i c r t} .
$$

Here, $I L_{\text {icrt }}$ measures the share of individual liability loans, measured either based on Number of Loans or based on the Gross Loan Portfolio of an MFI $i$ in country $c$, region $r$, and year $t . N P_{i}$ is an indicator variable for whether MFI $i$ is a non-profit, while $C_{c t}$ is a country-year level measure of competition. $a_{i c r}$ is an MFI, country, or region fixed effect, and $b_{t}$ is a year fixed effect. For robustness checks, we also control for further covariates that vary at the country level or the MFI level and are included in $\mathbf{X}_{i c t}$; these are discussed further below.

Mapping the tested predictions into parameter estimates: (1) non-profits have lower IL shares $(\alpha<0)$; (2) competition decreases the use of IL by forprofits $(\eta<0)$; (3) competition increases the use of IL by non-profits $(\eta+\gamma>0)$. We additionally test whether the effect of competition on non-profit IL shares is more positive than on for-profits $(\gamma>0)$.

We exploit variation at two levels. First, we exploit variation across MFIs within a region or country in order to estimate the coefficient $\alpha$, since the nonprofit indicator does not vary within MFI. For these specifications, we control for region or country fixed effects and year fixed effects. Secondly, we exploit 
variation within MFIs over time, in order to more cleanly identify how changes in competition $C_{c t}$ affect for-profit MFIs differently from non-profit MFIs. In these specifications we cannot estimate $\alpha$ because it is collinear with the fixed effects.

Sample sizes can change a little throughout the analysis, reflecting nonavailability of some variables for some observations.

\subsection{Main Results}

The main results are presented in Table 4. We present results for both the strongly and weakly balanced panels. The results are strongly supportive of Propositions 2 (non-profits use IL less) and 3 (for profits decrease IL usage when competition increases). They are less supportive of Proposition 1, which predicts a positive effect of competition on IL usage by non-profits. Our estimates are more consistent with a zero effect.

On average, we estimate that non-profits have lower IL shares, by around 10-20 percentage points. A 1 standard deviation increase in our competition measure is associated with a decrease in IL usage by for-profits, estimated at around 6-8 percentage points when country or MFI fixed effects are included. We find strong support for non-profits responding differently-the interaction coefficient $\gamma$ is consistently positive and significant when country or MFI fixed effects are included. However, the estimated net effect $(\eta+\gamma)$, while positive in most specifications, is close to zero and never significant.

\section{Robustness}

\subsection{Alternative sampling frame}

We might be concerned about representativeness of the MFIs in our main sample, which were not selected at random. Table 5 Panel A replicates our analysis in an alternative sampling frame that includes a more complete set of MFIs, at the cost of shortening the panel to 2008-2011. We find extremely similar results to our main specification, despite the number of MFIs in the balanced panel more than tripling, suggesting that sample selection (at least between these two samples) is not an important driver of the findings. 
We might also be concerned that measuring IL shares by number of loans overweights small loans. We therefore in table 5 Panel B replicate the analysis and results for IL shares measured by value (which are available in our second sample) rather than by number, again obtaining very similar results.

\subsection{Country- and MFI-level confounds}

The competition proxies may be capturing other macroeconomic trends or MFI characteristics. For example, if individual loans are difficult to administer in rural areas, differences in urbanization might be driving the effects we see. Or perhaps the shift towards IL lending reflects the growth of mobile banking, which can substitute for the transaction cost-lowering benefits of group lending.

Appendix Table C.2 controls for level effects and and interactions with the non-profit indicator for additional country level covariates in case the competition proxy is also proxying for these variables. We include the urban population share, mobile phones per 100 people, GDP per capita, service/industry sector shares in GDP, and foreign aid, all taken from the World Development Indicators. The signs, magnitudes and the precision of our main coefficients are robust to the inclusion of these additional controls. This suggests that the competition proxy measure is capturing distinct forces to changes in e.g. borrower incomes or country demographics.

Appendix Table C.3 checks robustness to inclusion of further control variables that vary at the country and MFI level. We control for non-linear countryspecific trends (using country-year fixed effects). This precludes estimation of the direct effect of the competition proxies (so we cannot test $\eta<0$ or $\eta+\gamma>0$ ), but we can still exploit within-country variation to analyze the differences in behavior of non-profits and for-profits, testing whether $\alpha<0$ and $\gamma>0$. We also

control for some MFI-level indicators (and/or fixed effects): a static measure capturing the MIX Market's assessment of the sustainability of an MFI's operations ("Diamonds"), and time-varying measures (namely, Capital to Asset Ratio, Debt to equity ratio, Average loan balance per borrower, Return on assets, Financial revenue/Assets, Yield on gross portfolio, Financial expense/assets ra- 
tio, and Operating expense/assets ratio). We lose some observations as not all variables are available for all MFIs. The coefficients remain stable relative to the main specifications, consistently estimating a lower IL share for non-profits and a more positive effect of competition on IL lending by non-profits than for-profits. ${ }^{35}$

\subsection{Cost of capital}

As discussed in section 3.5, lenders' cost of capital also affects the choice between individual and joint liability. Specifically, higher-cost non-profits are more likely to offer individual liability, as IC2 is less likely to be satisfied.

This is important to check because our proxy variables might be associated with lenders' cost of capital, for example because for-profit lenders have access to different funding sources than non-profits or because increased competition is associated with new funding sources coming available. If so, our main regressions could be omitting an important confound.

We explore this prediction empirically by including MFI-level measures of either total costs or financial costs (as a percentage of assets), interacted with profit status, in our main specification. Results are presented in Web Appendix Table C.4. It turns out that we see little systematic relationship between costs and contract choice, and the estimates are quite imprecise, so there is little to say either for or against the proposition. Encouragingly, however, our main results on lending by non-profits and for-profits are robust to including these cost measures.

\subsection{Competition measures}

Next, Web Appendix Table C.5 examines robustness to separating our competition measure into its three composite components. The first panel proxies

\footnotetext{
${ }^{35}$ While our model abstracts from loan size, for a given level of social capital $S$, growth in loan sizes (perhaps driven by income growth) also predicts a shift toward IL. This is because the larger the loan, the more social capital is required for a $\mathrm{JL}$ borrower to be willing to assist her partner, making low social capital JL groups no longer viable. It is therefore encouraging that our coefficient estimates are robust to inclusion of controls for GDP and loan size, because this gives confidence that the trend we observe is not simply capturing by other changes in lending behavior.
} 
competition with the number of bank branches per million inhabitants, the second with the number of ATMs per million and the third with "financial depth," the share of loans given by domestic financial institutions relative to GDP. Each variable is standardized to mean zero, standard deviation one. While a little noisier, the results are broadly consistent with our earlier findings. In particular we find consistent support for Propositions 2 and 3, but usually a zero effect of competition on non-profits.

\subsection{Regulatory changes}

Next, we might be concerned that the patterns we observe are driven by regulatory changes during our sample period which happen to correlate with our proxy variables. We attempt to address such concerns in Web Appendix Table C.6.

Panel A removes observations of MFIs whose legal status has changed during the sample period. The results remain unchanged. In panel $\mathrm{B}$, we control flexibly for time-varying regulatory shocks, using Region by Legal Status by Year fixed effects (legal status and for-profit status are correlated but not collinear). Under the assumption that regulation varies according to legal status and not profit status, this specification controls for time-varying regulatory shifts, albeit only at the regional and not country level.

Finally, we check how sensitive our results are to individual countries, by recomputing our main coefficients $(\alpha, \eta$, and $\eta+\gamma)$ for each competition measure and dropping each country in turn. Web Appendix Figure C.3 provides box plots of the coefficient estimates obtained in this exercise. While the results are sensitive to some countries (which specific countries depends on the competition measure), this only affects the sign of the estimated $\eta+\gamma$, which we already saw tends to be close to zero.

\subsection{Relaxing restrictions on the size of $U$}

As discussed in section 3.6, relaxing the assumption that IL is always profitable introduces a potential non-monotonicity: IL lending to low-S borrowers 
may shut down when borrowers' outside options are very good, leading to nonprofits' IL shares first increasing and then decreasing in $U$. This could lead us to underestimate the responsiveness of IL lending by non-profits to changes in $U$.

The driving force for the non-monotonicity in IL shares is the shutting down of all IL lending when $U$ is sufficiently high. Therefore we address the concern by restricting attention to intensive margin changes in IL lending. Table C.7 does this: in Panel A we drop all MFIs that ever report a portfolio that is either $0 \%$ or 100\% IL, while in Panel B we drop only individual MFI-years that meet this criterion. The estimates become somewhat more noisy, but the basic pattern is preserved in most cases. Interestingly and consistent with the prediction we also find a more positive effect of competition on IL usage by non-profits than in the main analysis.

\section{Discussion}

In this section we provide further discussion on the role of social capital in the model, and an informal discussion of possible extensions for future work.

\subsection{Social capital}

A key variable in our model is "social capital", which is used to sustain mutual insurance under joint liability. In the model, social capital plays a useful role by providing cutoff conditions at which lenders switch contract types, since we can write conditions for joint liability to be offered in terms of the minimum amount of social capital required (which differs by lender type). We then study how these thresholds change with the lender type and borrowers' outside option. The fact that the for-profit requires higher social capital to offer JL reflects that the space of parameters under which for-profits offer JL is smaller (in other words, we could perform our analysis fixing $S=0$, concluding that the condition for for-profits to offer JL is "stricter" than for non-profits). Our empirical analysis has assumed that social capital is either fixed or orthogonal to changes in our commercialization proxy variables. 
Field evidence supports the notion that social capital supports repayment of group loans. Feigenberg et al. (2013) find that increasing borrowing group meeting frequency led to creation of social capital, which in turn led to increases in mutual insurance among group members. ${ }^{36}$ Karlan (2007) exploits quasi-random variation in group assignment and shows that socially connected groups repay more often. Karlan (2005) finds that an experimental measure of trustworthiness, as well as survey questions on trust, predict good repayment behavior.

An alternative approach is to correlate proxies for social capital with lenders' portfolio composition. We only observe such characteristics at the country level, so the analysis is in essence a cross-country regression. Web Appendix C.8 presents some exploratory regressions, but we see little evidence that these are systematically correlated with lending methodology. ${ }^{37}$

\subsection{Further extensions}

One feature not present in our model is cross-subsidization (see e.g. McIntosh and Wydick (2005)). In the current framework we have assumed capital is scarce, leading to rationing. A non-profit wishing to provide credit to a broader user base might choose to offer a profitable IL contract to some borrowers (for whom JL might also be feasible), so as to allow it to offer loss-making contracts to other borrowers, thereby expanding the number of borrowers. Increased competition decreases the profitability of IL relative to JL (this is the mechanism that leads for-profits to switch contract types), so also reduces the benefit of cross-subsidization. This will tend to push non-profits to use IL less as competition increases, dampening the relationship between competition and IL lending.

\footnotetext{
${ }^{36}$ Strikingly, this study was conducted with group lending but individual liability contracts. However, the basic mechanism by which social capital sustains mutual insurance is the same as in joint liability lending, see de Quidt et al. (2016).

${ }^{37}$ We regress individual liability shares on various proxies, plus year and region fixed effects. We include the urban population share (as in table C.2), since social capital is plausibly higher in rural areas, and four questions on trust from the World Values Survey. Ideally we would like to observe the rural/urban composition of a given MFI's borrowers, so as to explore whether more rural MFIs within a given country are more likely to offer JL, but this information is not available.
} 
Thus we may underestimate the effect of competition on non-profits' IL shares.

Alternatively, if our proxy variables are associated with reduction in lenders' cost of financing, cross-subsidization motives might be diminished as competition increases, reducing the incentive to use IL. This would similarly dampen the relationship between the competition proxy and IL lending. The finding that the main results change little when we include cost measures suggests this is not a major concern.

Another possible extension would be to introduce within-group heterogeneity and a richer space of possible outcomes. This could be important if some joint liability borrowers are tempted to default on their own loans even when their partner is repaying, leading to use of social sanctions in more states of the world, and potentially blurring the boundary between individual and joint liability.

Alternatively, adverse selection (for example, a population of impatient borrowers with high default risk) might induce lenders to use dynamic contracts that screen out bad types, such as in Ghosh and Ray (2015). This, combined with the higher repayment rates under joint liability, might change the static trade-offs between contract types.

We conjecture, but leave to future work to prove, that the core mechanism introduced in this paper would survive these extensions. Namely, it is the interaction between the different slopes of the incentive conditions under individual and joint liability, with the different motivations of non-profit and for-profit, that drives the differences in contract offerings between the two.

\section{Conclusion}

While it is often claimed that joint liability is in decline, there has been little formal analysis beyond some allusions to JL being inconvenient for borrowers, who dislike having their social capital leveraged in this way. For this taste-based argument to have bite in explaining the trend, there must be a change in tastes over time, which is very difficult to test (in particular because we are aware of

no dataset that even attempts to measure such preferences). In this paper we show that even with stable tastes, commercialization can predict the decline. 
We provide a rigorous attempt to examine the trend empirically, and to analyze its cause. We show that MFIs do indeed appear to be reducing the share of joint liability in their portfolios. We argue theoretically that a key mechanism underlying the decline of JL is commercialization: a hand-in-hand increase in competition alongside a shift from non-profit to for-profit lending, and show that both trends are present in the data. While the analysis does not perfectly address endogeneity concerns, we test the model on a variety of sampling frames and with a stringent set of fixed effects and controls. Overall, we find the data are largely qualitatively consistent with the theory: non-profits do use joint liability more than for-profits; competition is associated with increasing use of joint liability by for-profits and with non-increasing or (in some specifications) decreasing use of joint liability by non-profits.

As our data are imperfect and our competition measure is based on proxies we avoid making strong quantitative claims based on our results. Also, in the absence of a natural experiment, we do not have a way of cleanly causally identifying the effect of changes in market structure on the switch from joint liability to individual liability. We hope that in the future our analysis can be complemented with more micro-level evidence on the mechanisms highlighted in the paper.

\section{Acknowledgements}

We thank Debraj Ray and several seminar audiences for helpful comments. We thank Chris Ahlin and Matthew Suandi for assistance with data, and John Kramer and Neelanjan Datta for research support. All errors and omissions are our own.

\section{References}

Christian Ahlin and Matthew Suandi. A Matter of Experience? Understanding the decline in group lending. Michigan State mimeo, 2018. 
Christian Ahlin and R M Townsend. Using Repayment Data to Test Across Models of Joint Liability Lending. The Economic Journal, 117(517):F11F51, 2007.

Christian Ahlin, Jocelyn Lin, and Michael Maio. Where does microfinance flourish? Microfinance institution performance in macroeconomic context. Journal of Development Economics, 95(2):105-120, 2011.

Treb Allen. Optimal (partial) group liability in microfinance lending. Journal of Development Economics, 121:201-216, 2016.

Beatriz Armendáriz de Aghion and Jonathan Morduch. The Economics of Microfinance, Second Edition. MIT Press Books. The MIT Press, Cambridge, MA, 2010. ISBN 9780262513982.

Orazio Attanasio, Britta Augsburg, Ralph De Haas, Emla Fitzsimons, and Heike Harmgart. The impacts of microfinance: Evidence from joint-liability lending in Mongolia. American Economic Journal: Applied Economics, 7(1):90-122, 2015.

Jean-Marie Baland, Rohini Somanathan, and Zaki Wahhaj. Repayment incentives and the distribution of gains from group lending. Journal of Development Economics, 105:131-139, 2013.

Abhijit Banerjee, Dean Karlan, and Jonathan Zinman. Six randomized evaluations of microcredit: Introduction and further steps. American Economic Journal: Applied Economics, 7(1):1-21, 2015.

Guillermo Baquero, Malika Hamadi, and Andréas Heinen. Competition, loan rates and information dispersion in microcredit markets. Journal of Money, Credit, and Banking, forthcoming.

Thorsten Beck. Reaching out: Access to and use of banking services across countries. Journal of Financial Economics, 85(1):234-266, 2007. 
Thorsten Beck, Asli Demirgüç-Kunt, and Vojislav Maksimovic. Bank Competition and Access to Finance: International Evidence. Journal of Money, Credit, and Banking, 36(3b):627-648, 2004.

Timothy Besley and Stephen Coate. Group lending, repayment incentives and social collateral. Journal of Development Economics, 46(1):1-18, 1995.

Emily Breza. Peer Effects and Loan Repayment: Evidence from the Krishna Default Crisis. Columbia mimeo, 2013.

Jeremy Bulow and Kenneth Rogoff. Sovereign Debt: Is to Forgive to Forget? The American Economic Review, 79(1):43-50, 1989.

Fenella Carpena, Shawn Cole, Jeremy Shapiro, and Bilal Zia. Liability structure in small-scale finance: Evidence from a natural experiment. The World Bank Economic Review, 27(3):437-469, 2013.

Alessandra Cassar and Bruce Wydick. Does social capital matter? Evidence from a five-country group lending experiment. Oxford Economic Papers, 62 (4):715-739, 2010.

Robert Cull, Asli Demirgüç-kunt, and Jonathan Morduch. Financial performance and outreach: a global analysis of leading microbanks. The Economic Journal, 117(517):F107-F133, 2007.

Robert Cull, Asli Demirgüç-kunt, and Jonathan Morduch. Microfinance meets the market. Journal of Economic Perspectives, 23(1):167-192, 2009.

Robert Cull, Asli Demirgüç-Kunt, and Jonathan Morduch. Banks and microbanks. Journal of Financial Services Research, 46(1):1-53, 2014.

Jonathan de Quidt, Thiemo Fetzer, and Maitreesh Ghatak. Group lending without joint liability. Journal of Development Economics, 121:217-236, 2016.

Jonathan de Quidt, Thiemo Fetzer, and Maitreesh Ghatak. Market Structure and Borrower Welfare in Microfinance. The Economic Journal, in press. 
Pascaline Dupas and Jonathan Robinson. Savings Constraints and Microenterprise Development: Evidence from a Field Experiment in Kenya. American Economic Journal: Applied Economics, 5(1):163-192, 2013a.

Pascaline Dupas and Jonathan Robinson. Why Don't the Poor Save More? Evidence from Health Savings Experiments. The American Economic Review, 103(4):1138-1171, 2013b.

Benjamin Feigenberg, Erica Field, and Rohini Pande. The Economic Returns to Social Interaction: Experimental Evidence from Microfinance. The Review of Economic Studies, 80(4):1459-1483, 2013.

Maitreesh Ghatak and Timothy W. Guinnane. The economics of lending with joint liability: theory and practice. Journal of Development Economics, 60 (1):195-228, 1999.

Parikshit Ghosh and Debraj Ray. Information and enforcement in informal credit markets. Economica, 83(329):59-90, 2015.

Xavier Giné and Dean S. Karlan. Group versus individual liability: Short and long term evidence from Philippine microcredit lending groups. Journal of Development Economics, 107:65-83, 2014.

Xavier Giné, Karuna Krishnaswamy, and Alejandro Ponce. Strategic Default in joint liability groups: Evidence from a natural experiment in India. World Bank mimeo, 2011.

Niels Hermes and Robert Lensink. The empirics of microfinance: what do we know? The Economic Journal, 117(517):F1-F10, 2007.

Karla Hoff and Joseph Stiglitz. Moneylenders and bankers: price-increasing subsidies in a monopolistically competitive market. Journal of Development Economics, 52(2):429-462, 1997.

Dean S. Karlan. Using Experimental Economics to Measure Social Capital and Predict Financial Decisions. The American Economic Review, 95(5):16881699, 2005. 
Dean S. Karlan. Social connections and group banking. The Economic Journal, 117(517):F52-F84, 2007.

Dean S. Karlan and Jonathan Zinman. Expanding Credit Access: Using Randomized Supply Decisions to Estimate the Impacts. Review of Financial Studies, 23(1):433-464, 2009a.

Dean S. Karlan and Jonathan Zinman. Expanding microenterprise credit access: Using randomized supply decisions to estimate the impacts in Manila. Yale Economics Department Working Paper No. 68, 2009b.

Ross Levine. Finance and Growth: Theory and Evidence, volume 1, chapter 12, pages 865-934. North Holland, 2005.

Mahreen Mahmud. Repaying Microcredit Loans: A Natural Experiment on Liability Structure. Kent Discussion Paper in Economics 1509, 2015.

Craig McIntosh and Bruce Wydick. Competition and microfinance. Journal of Development Economics, 78(2):271-298, 2005.

Craig McIntosh, Alain De Janvry, and Elisabeth Sadoulet. How rising competition among microfinance institutions affects incumbent lenders. The Economic Journal, 115(506):987-1004, 2005.

Roy Mersland and R. Øystein Strøm. Performance and governance in microfinance institutions. Journal of Banking E Finance, 33(4):662-669, 2009.

Carl Shapiro and Joseph E. Stiglitz. Equilibrium unemployment as a worker discipline device. The American Economic Review, 74(3):433-444, 1984.

Martin Čihák, Asli Demirgüč-Kunt, Erik Feyen, and Ross Levine. Financial Development in 205 Economies, 1960 to 2010. Journal of Financial Perspectives, $1(2): 17-36,2013$. 


\section{Figures and tables}

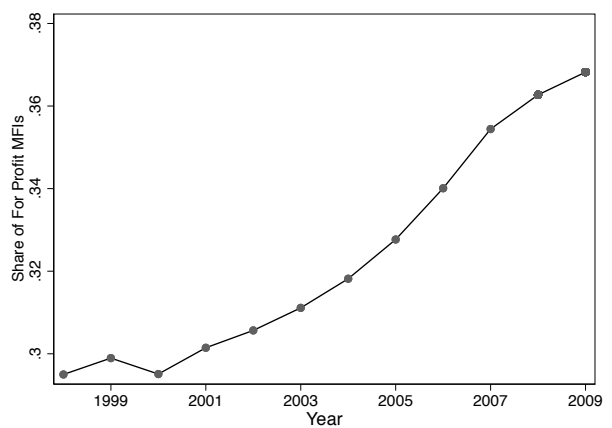

(a) Growth in share of for-profit MFIs

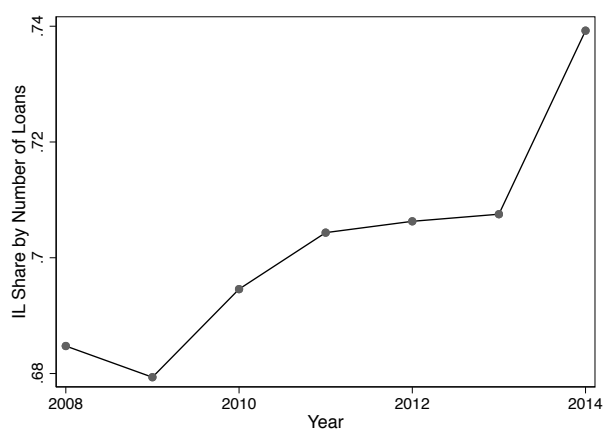

(c) Growth of individual liability

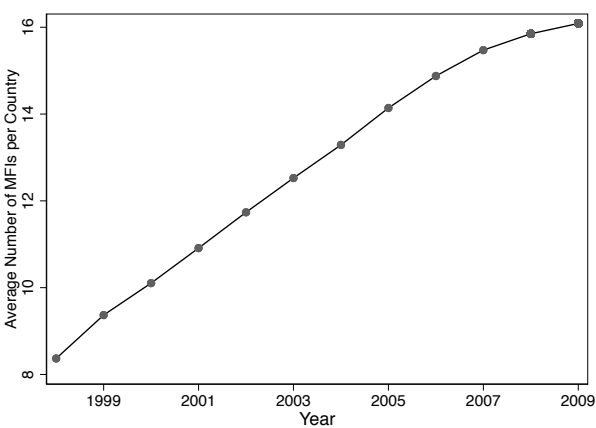

(b) Growth in competition

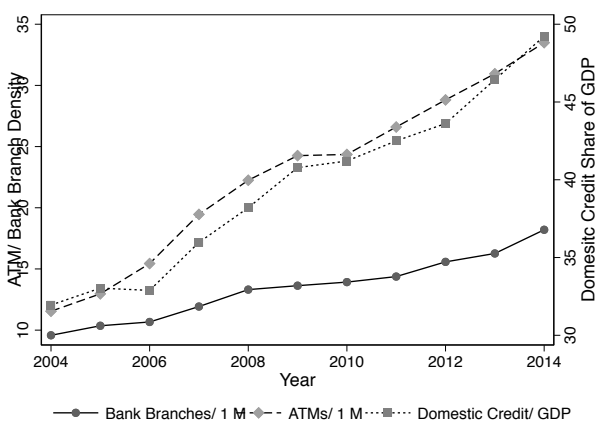

(d) Growth of competition proxies

Figure 1: Stylized Facts. (a) plots the share of microfinance institutions that operate for profit. (b) plots the average number of microfinance institutions per country. (c) plots the share of lenders' portfolios that are individual liability loans. (d) plots three proxies for microcredit commercializations: the ratio of bank branches and ATMs to population, and the domestic credit/GDP ratio. 


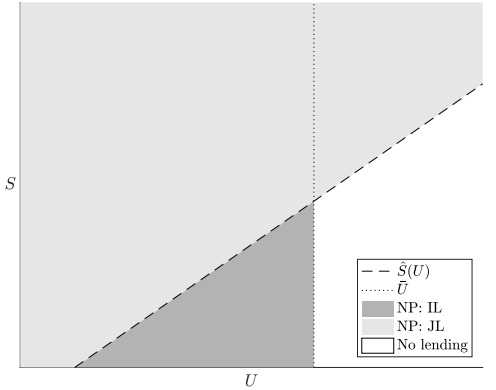

(a) Non-profit

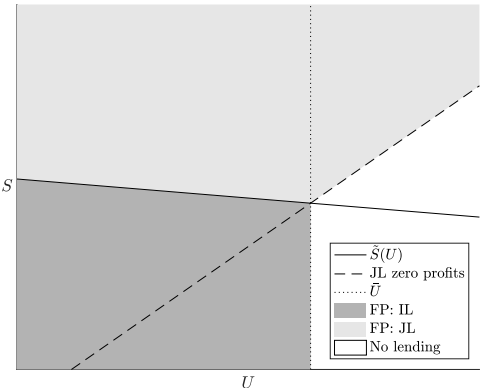

(b) For-profit

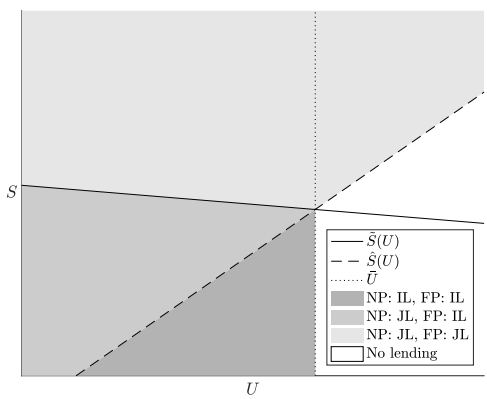

(c) Non-profit and for-profit

Figure 2: Contract regions. (a) plots the regions over which a non-profit lender offers JL or IL. (b) plots the the regions over which a non-profit lender offers JL or IL. (c) combines (a) and (b) in a single plot. 
Table 2: MFI Characteristics for MFIs reporting IL share by Number of Loans

\begin{tabular}{|c|c|c|c|c|c|c|c|c|}
\hline & \multicolumn{2}{|c|}{ Full Sample } & \multicolumn{3}{|c|}{ Fully Balanced } & \multicolumn{3}{|c|}{ Weakly Balanced } \\
\hline & Mean & $\mathrm{N}$ & Mean & $\mathrm{N}$ & $\mathrm{p}$ & Mean & $\mathrm{N}$ & $\mathrm{p}$ \\
\hline Portfolio at risk 90 days & 6.28 & 1943 & 5.32 & 111 & 0.52 & 4.64 & 548 & 0.03 \\
\hline Loan Loss Rate & 2.85 & 1819 & 1.48 & 111 & 0.07 & 2.78 & 548 & 0.94 \\
\hline Risk coverage & 415.43 & 1704 & 879.61 & 111 & 0.50 & 336.89 & 548 & 0.60 \\
\hline Real Yield & 23.80 & 1836 & 23.90 & 111 & 0.97 & 27.04 & 548 & 0.02 \\
\hline Nominal Yield & 33.30 & 1837 & 31.62 & 111 & 0.49 & 34.78 & 548 & 0.33 \\
\hline Non-profit status & 0.49 & 2176 & 0.67 & 111 & 0.01 & 0.60 & 548 & $<0.01$ \\
\hline MIX Market Diamonds & 2.60 & 2124 & 4.05 & 111 & $<0.01$ & 3.31 & 548 & $<0.01$ \\
\hline Operational Self Sufficiency & 113.70 & 2004 & 112.26 & 111 & 0.62 & 114.65 & 548 & 0.72 \\
\hline Financial Expenses/ Assets & 5.40 & 1860 & 5.48 & 111 & 0.90 & 5.42 & 548 & 0.95 \\
\hline Personnel Expenses/ Assets & 10.87 & 1824 & 10.32 & 111 & 0.63 & 11.11 & 548 & 0.78 \\
\hline Admin Expenses/ Assets & 9.54 & 1855 & 7.09 & 111 & 0.01 & 8.30 & 548 & 0.12 \\
\hline Profit margin & 666.74 & 1999 & 7.48 & 111 & 0.75 & 7.74 & 548 & 0.75 \\
\hline Return on Assets & -0.94 & 1886 & 2.01 & 111 & $<0.01$ & 1.40 & 548 & $<0.01$ \\
\hline Return on Equity & 4.85 & 1881 & 1.63 & 111 & 0.71 & 7.05 & 548 & 0.76 \\
\hline Gross Loan Portfolio/ Assets & 74.57 & 2088 & 79.46 & 111 & 0.05 & 77.64 & 548 & 0.13 \\
\hline Debt to Equity Ratio & 7.06 & 2027 & 3.61 & 111 & 0.32 & 5.23 & 548 & 0.58 \\
\hline Cost per borrower & 334.70 & 1660 & 243.21 & 111 & 0.09 & 280.82 & 548 & 0.28 \\
\hline Average Loan Balance per borrower & 8131.41 & 2060 & 1428.31 & 111 & 0.08 & 1660.03 & 548 & 0.09 \\
\hline Share of female borrowers & 62.05 & 1935 & 56.79 & 111 & 0.16 & 59.77 & 548 & 0.47 \\
\hline Number of Borrowers (in 1000s) & 53.12 & 2066 & 44.23 & 111 & 0.61 & 68.52 & 548 & 0.31 \\
\hline Total Assets (in 1000 USD) & 54642.83 & 2098 & 46780.25 & 111 & 0.55 & 78734.57 & 548 & 0.11 \\
\hline Gross Loan Portfolio (in 1000 USD) & 48588.75 & 2164 & 37408.97 & 111 & 0.42 & 64207.89 & 548 & 0.32 \\
\hline
\end{tabular}

Notes: Comparison of sample means across different samples used in the main table. Weakly balanced refers to MFIs reporting lending method by number of loans at least twice from 2008 - 2014, while fully balanced only includes MFIs that report data on lending method by number of loans in each year between 2008-2014. We report the 2009 values where available (since 2009 has the greatest data availability), otherwise we take the closest available datapoint (averaging 2008 and 2010 when both are available). The number of MFIs changes as not all institutions report data on all the characteristics explored. "Mean" reports the average of the characteristic, "N" reports the number of MFIs included in the sample, while "p-value" reports the significance of the difference in means between the respective sample and the remainder of the full sample.

Table 3: Country characteristics

\begin{tabular}{|c|c|c|c|c|c|c|c|c|}
\hline & \multicolumn{2}{|c|}{ Full Sample } & \multicolumn{3}{|c|}{ Fully Balanced } & \multicolumn{3}{|c|}{ Weakly Balanced } \\
\hline & Mean & $\mathrm{N}$ & Mean & $\mathrm{N}$ & $\mathrm{p}$ & Mean & $\mathrm{N}$ & $\mathrm{p}$ \\
\hline Urban population share & 46.83 & 120 & 54.73 & 37 & $<0.01$ & 49.46 & 81 & 0.05 \\
\hline Mobile Phones/100 people & 65.30 & 121 & 81.73 & 37 & $<0.01$ & 67.51 & 81 & 0.31 \\
\hline Agriculture share in GDP & 17.98 & 115 & 13.60 & 37 & $<0.01$ & 17.18 & 81 & 0.37 \\
\hline Industrial sector share in GDP & 28.62 & 115 & 29.48 & 37 & 0.51 & 29.32 & 81 & 0.37 \\
\hline Service sector share in GDP & 53.22 & 115 & 56.90 & 37 & 0.01 & 53.27 & 81 & 0.95 \\
\hline Development Aid per capita & 82.93 & 115 & 82.04 & 37 & 0.95 & 79.33 & 81 & 0.60 \\
\hline GDP Growth Rate & 4.14 & 121 & 4.29 & 37 & 0.70 & 4.13 & 81 & 0.96 \\
\hline GDP per capita & 3627.77 & 121 & 3726.17 & 37 & 0.81 & 3361.64 & 81 & 0.31 \\
\hline Domestic Credit / GDP & 43.52 & 120 & 45.10 & 37 & 0.70 & 39.84 & 81 & 0.14 \\
\hline Commercial bank density & 12.59 & 121 & 18.68 & 37 & $<0.01$ & 13.71 & 81 & 0.14 \\
\hline ATM Density & 21.87 & 119 & 29.25 & 37 & 0.02 & 22.28 & 81 & 0.76 \\
\hline
\end{tabular}

Notes: "Full sample" contains country-level characteristics for the countries represented in the full MIX sample, while "weakly balanced" and "fully balanced" restrict to the countries that appear in the respective panels (the "number of loans" samples). We report unweighted averages, i.e. each country is given equal weight irrespective of the number or scale of MFIs in that country for 2009. The number of countries changes as not all countries have data for all characteristics. "Mean" reports the average of the characteristic, "N" reports the number of countries included in the sample, while "p-value" reports the significance of the difference in means between the respective sample and the remainder of the full sample. 
Table 4: Non Profit Status, Competition and IL Lending

\begin{tabular}{|c|c|c|c|c|c|c|}
\hline & \multicolumn{3}{|c|}{ Fully Balanced } & \multicolumn{3}{|c|}{ Weakly Balanced } \\
\hline & (1) & $(2)$ & $(3)$ & (4) & $(5)$ & (6) \\
\hline Competition First PC & $\begin{array}{l}-0.023 \\
(0.041)\end{array}$ & $\begin{array}{c}-0.079^{* *} \\
(0.030)\end{array}$ & $\begin{array}{c}-0.069^{* * *} \\
(0.011)\end{array}$ & $\begin{array}{l}-0.042 \\
(0.036)\end{array}$ & $\begin{array}{c}-0.066^{* *} \\
(0.028)\end{array}$ & $\begin{array}{c}-0.061 * * * \\
(0.016)\end{array}$ \\
\hline Non Profit & $\begin{array}{l}-0.123^{*} \\
(0.068)\end{array}$ & $\begin{array}{l}-0.116 \\
(0.081)\end{array}$ & & $\begin{array}{c}-0.126^{* *} \\
(0.050)\end{array}$ & $\begin{array}{c}-0.175^{* * *} \\
(0.040)\end{array}$ & \\
\hline Non Profit $\mathrm{x}$ Competition First PC & $\begin{array}{c}0.050 \\
(0.052)\end{array}$ & $\begin{array}{l}0.096^{*} \\
(0.048)\end{array}$ & $\begin{array}{c}0.076^{* * *} \\
(0.019)\end{array}$ & $\begin{array}{c}0.036 \\
(0.027)\end{array}$ & $\begin{array}{c}0.084^{* * *} \\
(0.028)\end{array}$ & $\begin{array}{c}0.065^{* * *} \\
(0.019)\end{array}$ \\
\hline $\begin{array}{l}\text { Joint test: } \\
\text { Comp }+ \text { Non-Profit } \mathrm{x} \text { Comp }=0 ?\end{array}$ & $\begin{array}{c}.027 \\
(.0515)\end{array}$ & $\begin{array}{c}.016 \\
(.0242)\end{array}$ & $\begin{array}{c}.007 \\
(.0205)\end{array}$ & $\begin{array}{c}-.006 \\
(.0361)\end{array}$ & $\begin{array}{c}.018 \\
(.0177)\end{array}$ & $\begin{array}{c}.004 \\
(.0166)\end{array}$ \\
\hline MFIs & 111 & 111 & 111 & 548 & 548 & 548 \\
\hline Countries & 37 & 37 & 37 & 81 & 81 & 81 \\
\hline Observations & 769 & 769 & 769 & 2573 & 2573 & 2573 \\
\hline Year FE & $\mathrm{X}$ & $\mathrm{X}$ & $\mathrm{X}$ & $\mathrm{X}$ & $\mathrm{X}$ & $\mathrm{X}$ \\
\hline Region FE & $\mathrm{X}$ & & & $\mathrm{X}$ & & \\
\hline Country FE & & $\mathrm{X}$ & & & $\mathrm{X}$ & \\
\hline MFI FE & & & $X$ & & & $\mathrm{X}$ \\
\hline
\end{tabular}

Notes: The dependent variable is the share of individual liability loans provided by an MFI as measured by Number of Loans. Fully balanced refers to a balanced dataset for which lending methodology data is available for all years between 2008 and 2014, while weakly balanced includes only MFIs that report this information at least twice. Standard errors in parentheses are clustered at the country level, with stars indicating ${ }^{* * *} p<0.01,{ }^{* *} p<0.05,{ }^{*} p<0.1$. 


\begin{tabular}{|c|c|c|c|c|c|c|}
\hline \multirow[t]{2}{*}{ Panel A: IL Share by Number of Loans } & \multicolumn{3}{|c|}{ Fully Balanced } & \multicolumn{3}{|c|}{ Weakly Balanced } \\
\hline & (1) & (2) & (3) & (4) & (5) & (6) \\
\hline Competition PCA & $\begin{array}{c}-0.067^{*} \\
(0.037)\end{array}$ & $\begin{array}{c}-0.077^{* *} \\
(0.030)\end{array}$ & $\begin{array}{l}-0.026 \\
(0.019)\end{array}$ & $\begin{array}{c}-0.064^{* * *} \\
(0.022)\end{array}$ & $\begin{array}{l}-0.044^{*} \\
(0.024)\end{array}$ & $\begin{array}{c}-0.031^{*} \\
(0.017)\end{array}$ \\
\hline Non Profit & $\begin{array}{c}-0.174^{* * *} \\
(0.058)\end{array}$ & $\begin{array}{c}-0.230^{* * *} \\
(0.072)\end{array}$ & & $\begin{array}{c}-0.124^{* *} \\
(0.052)\end{array}$ & $\begin{array}{c}-0.200^{* * *} \\
(0.047)\end{array}$ & \\
\hline Non Profit x Competition PCA & $\begin{array}{l}0.058^{*} \\
(0.029)\end{array}$ & $\begin{array}{c}0.083^{* *} \\
(0.033)\end{array}$ & $\begin{array}{c}0.020 \\
(0.018)\end{array}$ & $\begin{array}{c}0.050^{* *} \\
(0.021)\end{array}$ & $\begin{array}{c}0.045^{* *} \\
(0.023)\end{array}$ & $\begin{array}{l}0.027^{*} \\
(0.015)\end{array}$ \\
\hline \multicolumn{7}{|l|}{ Joint test: } \\
\hline Comp + Non-Profit $x$ Comp $=0 ?$ & $\begin{array}{l}-.009 \\
(.0237)\end{array}$ & $\begin{array}{c}.007 \\
(.0147)\end{array}$ & $\begin{array}{l}-.006 \\
(.015) \\
\end{array}$ & $\begin{array}{l}-.015 \\
(.0181)\end{array}$ & $\begin{array}{c}.001 \\
(.0163)\end{array}$ & $\begin{array}{c}-.004 \\
(.00905) \\
\end{array}$ \\
\hline MFIs & 366 & 366 & 366 & 874 & 874 & 874 \\
\hline Countries & 61 & 61 & 61 & 87 & 87 & 87 \\
\hline Observations & 1428 & 1422 & 1428 & 2705 & 2694 & 2705 \\
\hline \multirow[t]{2}{*}{ Panel B: IL Share by Gross Loan Portfolio } & \multicolumn{3}{|c|}{ Fully Balanced } & \multicolumn{3}{|c|}{ Weakly Balanced } \\
\hline & (1) & (2) & (3) & (4) & (5) & (6) \\
\hline Competition PCA & $\begin{array}{c}-0.100^{* * *} \\
(0.026)\end{array}$ & $\begin{array}{c}-0.072^{* * *} \\
(0.022)\end{array}$ & $\begin{array}{l}-0.023 \\
(0.015)\end{array}$ & $\begin{array}{c}-0.085^{* * *} \\
(0.018)\end{array}$ & $\begin{array}{c}-0.051^{* *} \\
(0.023)\end{array}$ & $\begin{array}{c}-0.029^{*} \\
(0.015)\end{array}$ \\
\hline Non Profit & $\begin{array}{c}-0.182^{* * * *} \\
(0.045)\end{array}$ & $\begin{array}{c}-0.220^{* * *} \\
(0.051)\end{array}$ & & $\begin{array}{c}-0.145^{* * *} \\
(0.043)\end{array}$ & $\begin{array}{c}-0.201^{* * *} \\
(0.040)\end{array}$ & \\
\hline Non Profit x Competition PCA & $\begin{array}{c}0.072^{* * *} \\
(0.022)\end{array}$ & $\begin{array}{c}0.096^{* * *} \\
(0.024)\end{array}$ & $\begin{array}{l}0.032^{*} \\
(0.019)\end{array}$ & $\begin{array}{c}0.058^{* * *} \\
(0.019)\end{array}$ & $\begin{array}{c}0.059^{* * * *} \\
(0.019)\end{array}$ & $\begin{array}{l}0.026^{*} \\
(0.015)\end{array}$ \\
\hline \multicolumn{7}{|l|}{ Joint test: } \\
\hline Comp + Non-Profit $\mathrm{x}$ Comp $=0 ?$ & $\begin{array}{c}-.028 \\
(.0177)\end{array}$ & $\begin{array}{c}.024^{*} \\
(.0138)\end{array}$ & $\begin{array}{c}.009 \\
(.0175) \\
\end{array}$ & $\begin{array}{l}-.027^{*} \\
(.0153)\end{array}$ & $\begin{array}{c}.008 \\
(.0155) \\
\end{array}$ & $\begin{array}{c}-.002 \\
(.0125)\end{array}$ \\
\hline MFIs & 359 & 359 & 359 & 828 & 828 & 828 \\
\hline Countries & 58 & 58 & 58 & 86 & 86 & 86 \\
\hline Observations & 1399 & 1393 & 1399 & 2552 & 2542 & 2552 \\
\hline Year FE & $\mathrm{X}$ & $\mathrm{X}$ & $\mathrm{X}$ & $\mathrm{X}$ & $\mathrm{X}$ & $\mathrm{X}$ \\
\hline Region FE & $\mathrm{X}$ & & & $\mathrm{X}$ & & \\
\hline Country FE & & $\mathrm{X}$ & & & $\mathrm{X}$ & \\
\hline MFI FE & & & $\mathrm{X}$ & & & $\mathrm{X}$ \\
\hline
\end{tabular}




\title{
Appendix to "Commercialization and the Decline of Joint Liability Microcredit"
}

\author{
For Online Publication
}

\section{Appendix A. Data Appendix}

We combine three different data sets from the MIX Market and data from the World Bank's World Development Indicators. This note will outline the process by which we combine these different data sources to arrive at the data set we use in our paper.

Global Data Download. The MIX, in the past, provided a global data download of basic portfolio information. Unfortunately, access to the MIX market data has become more restrictive requiring an account and even paid subscriptions for some reports. We rely on the last snapshot of the global data download that is available via the WayBackMachine on https://web.archive.org/web/

20150215000000*/http://www .mixmarket.org/crossmarket-analysis-report/ download.

The global data download contains basic profile information, such as the MFI name, the respective MIX Market identification number, Profit status, Legal status as well as the basic portfolio report, detailing the Number of Loans Outstanding, Portfolio At Risk and other measures of performance that vary at the MFI level over time. We drop MFIs for which the Profit Status information is missing. We match the various financial years to the nearest calendar years. Unfortunately this comprehensive data download does not provide a detailed breakdown of lending methodology.

Further, we map the country names into 16 world regions: Central Africa, Central America, Central Asia, East Asia, Eastern Africa, Indian Ocean, Northern Africa, Northern Asia, South America, South Asia, South East Asia, South East Europe, South West Asia, Southern Africa, West Indies, Western Africa. 
This region definition is finer than the one used by the MIX market, which only distinguishes continent.

This is our basic MFI-level panel, which we augment with auxiliary data obtained from detailed portfolio reports to obtain information about lending methodology.

Detailed Portfolio Reports. Information on the lending methodology was collected manually by Ahlin and Suandi (2018), who kindly shared this data with us. They follow in their sampling broadly the same approach as used in Ahlin et al. (2011). The data set is selected to meet a range of criteria:

- Since MIX did not report information on lending methodology before 2008, the dataset only covers the period from 2008-2014. This discards around $40 \%$ of the observations which came from prior to 2008 , with the earliest data stemming from 1996.

- Only MFIs who report data by calendar-year are included, which lines up with the World Development Indicator variables we use, which are reported by calendar year. The vast majority ( $82 \%)$ of MFI-year observations are reported at the calendar year.

- Using the filters provided by the MIX Market website, the set of MFIs is restricted to MFIs that are classified as having four or five "diamonds" (in the year the download took place - late 2015).

- Lastly, MFIs reporting more than 20 percent of their current operations as non-microfinance related are excluded.

The selectness of our sample relative to the population of MFIs that report data to the MIX is explored in Table 2.

Incorporation Date and Profit Status. In order to construct the top left panel of Figure 1, we obtain data on the incorporation dates of the MFIs. Unfortunately, this information is not contained in the main data download. We make use of an older data download which provides this information for the 
set of MFIs that reported some data to the MIX market prior to February 2011. This data is not available on the main website anymore, but can be retrieved from https://web.archive.org/web/*/http://www.mixmarket.org/ sites/default/files/mfi_profile_information_02.24.11.xls. We merge the date established to the global data download to construct the share of forprofit MFIs by incorporation dates. Obviously, this can only be constructed for the set of MFIs for which we know the incorporation date, in order to illustrate the global trend the figure also includes MFIs that do not disclose data on lending methodology. The figure looks very similar when weighting by MFI size in 2009 or by including e.g. only on the MFIs from the weakly balanced sample.

In addition, the 2011 data snapshot provides us with an additional record of the For-profit/non-profit status ("profit status") as of February 2011. One concern might be that some MFIs changed status prior to February 2011 (or between February 2011 and the end of 2011). Since legal status and non profit status are likely closely related (see Appendix Table C.1), we remove MFIs that switched legal status during our sample period. The results are presented in Table C.6.

Competition Proxies. Lastly, we obtain proxy variables for the extent of competition from the development indicators. These can be obtained from the World Bank Website, available at http://data.worldbank.org/

data-catalog/world-development-indicators.

We use these data as proxies for the borrowers' outside options, the availability of alternative sources of credit. Figure 1 plots the cross-country averages over time including the set of countries that are included in our weakly balanced panel frame (which includes some country-year observations in which individual indicators are missing) in these measures for the set of countries that appear in the full MIX dataset. Again, the trends look similar when focusing only on the countries which are present in our weakly balanced sample.

In order to combine the information contained in the three proxy variables, we construct their first principal component. The goal of principal component 
analysis is to produce a low-dimensional representation of a dataset by finding a set of orthogonal linear combinations of the (standardized) variables that have maximal variance. The first principal component is a variable $Z$ that is a linear combination of our three proxy variables $X_{1}, X_{2}, X_{3}$ :

$$
Z=\phi_{1} X_{1}+\phi_{2} X_{2}+\phi_{3} X_{3}
$$

fixing $\sum_{i} \phi_{i}^{2}=1$, such that $\operatorname{Var}(Z)$ is maximized. The second principal component is constructed to maximize variance subject to being orthogonal to $Z$, etc.

The $\phi$ s for the each principal component are given by the corresponding eigenvector of the correlation matrix of the standardized proxy variables. The matrix of eigenvectors is provided in Table A.1. The associated eigenvalues give the variance of the principal components, and since the principal components are orthogonal from these one can compute the fraction of the variance of the proxies explained by each principal component. The first principal component in our case accounts for $52.5 \%$ of the variation in the three proxies.

Table A.1: Matrix of Eigenvectors

\begin{tabular}{lccc}
\hline \hline & $\mathrm{e}(\mathrm{L})$ & & \\
& Comp1 & Comp2 & Comp3 \\
\hline Commercial bank density & .5425762 & .7177629 & .43638 \\
ATM Density & .6361516 & -.0118496 & -.7714731 \\
Domestic Credit / GDP & .5485638 & -.6961867 & .4630353 \\
\hline \hline
\end{tabular}

We can also compute the loadings of the first principal component, which are the correlations between the original variables and the first principal component. These are informative of the extent to which each variable contributes to the first principal component. The factor loadings are given in Table A.2. 
Table A.2: Factor Loadings

\begin{tabular}{lc}
\hline \hline & $(1)$ \\
& $\mathrm{r} 1$ \\
\hline Competition First PC & 1 \\
Commercial bank density & .6807061 \\
ATM Density & .7981041 \\
Domestic Credit / GDP & .6882182 \\
\hline \hline
\end{tabular}

World Values Survey. We downloaded the most recent release of the World Values Survey (WVS) Longitudinal dataset, available at http://www . worldvaluessurvey . org/WVSDocumentationWVL. jsp, which combines survey data across all the six waves to construct cross-sectional proxy variables for social capital across a broad set of countries. We focused on the trust measures as these are most widely included across the different survey waves allowing broad coverage. We compute four measures summarizing the average respondent's response to four trust-related questions. First, we compute the share of respondents who agree with the statement that "Most people can be trusted." The three other questions that have less coverage across survey waves ask respondents whether respondents trust "People you know personally," "People you have just met," or "Members of your family." For these questions, the responses are provided on a four point Likert scale. We compute the share pertaining to the number of respondents who either state that they "Trust completely" or "Trust somewhat", as opposed to stating "Do not trust very much" or "Do not trust at all." The correlation patterns we document here do not become stronger if we only compute the share of respondents who "Trust completely." 


\section{Appendix B. Theory Appendix}

Appendix B.1. Derivation of steady-state $I L / J L$ shares

The non-profit IL share in period $t$ is as follows:

$$
\hat{\eta}_{t}=\hat{\eta}_{t-1} p+\hat{\eta}_{t-1}(1-p) F(\hat{S}(U))+\left(1-\hat{\eta}_{t-1}\right)(1-q) F(\hat{S}(U))
$$

The first term on the right-hand side corresponds to the non-defaulting IL borrowers (fraction $p$ of the $\hat{\eta}_{t-1}$ IL borrowers), who retain their IL contracts. The second term corresponds to the vacancies at formerly IL branches which are filled by new IL borrowers (fraction $1-p$ of the $\hat{\eta}_{t-1}$ borrowers default creating vacancies, and then new borrowers are drawn of whom fraction $F(\hat{S})$ receive IL and $1-F(\hat{S})$ receive JL). The third term corresponds to the vacancies at formerly JL branches which are now filled by IL borrowers (fraction $1-q=(1-p)^{2}$ JL borrowers default creating vacancies, and then new borrowers are drawn of whom fraction $F(\hat{S})$ receive IL and $1-F(\hat{S})$ receive JL).

Solving this equation for the steady state by setting $\hat{\eta}_{t}=\hat{\eta}_{t-1}$ we obtain:

$$
\hat{\eta}(U)=\frac{F(\hat{S}(U))(1-p)}{1-F(\hat{S}(U)) p}
$$

The steady state JL share is equal to $1-\hat{\eta}(U)$. The for-profit derivations are identical.

Appendix B.2. Endogenizing $U$

We take the simplest case, where social capital is homogeneous and equal to $S$ for all borrowers. Since social capital is assumed to be observable one could model the market with heterogeneous $S$ as being segmented into separate markets corresponding to each possible value of $S$, by repeating the below analysis.

The population of borrowers has measure 2, but it is simpler to work in terms of the measure of pairs of borrowers, which has measure 1. The measure of lenders is $l<1$ (recall that each lender can serve two borrowers, and that if $l>1$ then all borrowers can guarantee they receive a loan every period, so have no incentive to repay their current loan). Since there is excess demand for 
credit, $l$ borrower pairs are served each period. Thus there are $l f$ for-profits and $l(1-f)$ non-profits.

Each period some borrowers default, leaving vacancies at their branches. We allow for the possibility that some lenders offer IL and some offer JL, and since borrowers are homogeneous we assume that their probability of receiving a given contract equals their probability of matching to a lender offering that contract. Thus, because of defaults, $l f \tilde{\eta}(U)(1-p)$ for-profit IL vacancies, $l f(1-\tilde{\eta})(1-q)$ for-profit JL vacancies, $l(1-f) \hat{\eta}(U)(1-p)$ non-profit IL vacancies and $l(1-$ $f)(1-\hat{\eta})(1-q)$ non-profit JL vacancies open each period. The total measure of unmatched borrowers, which we define as $D(U)$, is the number of defaulters last period plus the excess demand, $1-l$, equalling:

$$
\begin{aligned}
D(U) & =1-l+l[f \tilde{\eta}(U)(1-p)+(1-f) \hat{\eta}(U)(1-p) \\
& +f(1-\tilde{\eta}(U))(1-q)+(1-f)(1-\hat{\eta}(U))(1-q)] .
\end{aligned}
$$

Hence, an unmatched borrower can expect to receive:

$$
\begin{aligned}
U & =\frac{1}{D(U)}\left[l f \tilde{\eta}(U)(1-p) \tilde{V}^{I L}(U, S)+l(1-f) \hat{\eta}(U)(1-p) \hat{V}^{I L}(U)\right. \\
& +l f(1-\tilde{\eta}(U))(1-q) \tilde{V}^{J L}(U)+l(1-f)(1-\hat{\eta}(U))(1-q) \hat{V}^{J L}(U) \\
& +(1-l) \delta U] .
\end{aligned}
$$

An equilibrium obtains at a fixed point whereby lenders do not want to change their contract offerings given the value of $U$. We do not proceed with an in-depth analysis, but we note that there at least exist all-IL $(\tilde{\eta}=\hat{\eta}=1)$ and all-JL $(\tilde{\eta}=\hat{\eta}=0)$ equilibria. This follows from the analysis of competitive equilibrium in de Quidt et al. (in press), where we derive as a function of $S$ the value of $l$ such that all lenders earn zero profits. Except for a unique value for $S$ (at which both contracts break even) the equilibrium involves either all lenders offering IL (when $S$ is low) or all lenders offering JL (when $S$ is high). Since we have not assumed competitive equilibrium here there will also be cases where non-profits offer only JL and for-profits offer only IL, when $S \in(\hat{S}(U), \tilde{S}(U)]$. There will also be cases where one or potentially both lender types offer some IL and some JL. 
While a complete analysis is beyond the scope of this exercise, we show one result, that $U$ is increasing in $l$, as would naturally be expected. Intuitively, the more lenders are present in the market. We show this holding the $\eta$ s constant, i.e. assuming the composition of loan contracts remains unchained (which holds when $S \neq \hat{S}(U)$ and $S \neq \tilde{S}(U))$.

First, a little rearranging yields:

$$
\begin{aligned}
U D(U) & =U l[f \tilde{\eta}(U)(1-p)+(1-f) \hat{\eta}(U)(1-p) \\
& +f(1-\tilde{\eta}(U))(1-q)+(1-f)(1-\hat{\eta}(U))(1-q)]+(1-l) \delta U \\
& +l\left[f \tilde{\eta}(U)(1-p)\left(\tilde{V}^{I L}(U, S)-U\right)\right. \\
& +(1-f) \hat{\eta}(U)(1-p)\left(\hat{V}^{I L}(U)-U\right) \\
& +f(1-\tilde{\eta}(U))(1-q)\left(\tilde{V}^{J L}(U)-U\right) \\
& \left.+(1-f)(1-\hat{\eta}(U))(1-q)\left(\hat{V}^{J L}(U)-U\right)\right] .
\end{aligned}
$$

Rearranging some more, using the expression for $D(U)$, and substituting for the $V \mathrm{~s}:$

$$
\begin{aligned}
U(1-l)(1-\delta) & =l\left[f \tilde{\eta}(U)(1-p)\left(\tilde{V}^{I L}(U, S)-U\right)\right. \\
& +(1-f) \hat{\eta}(U)(1-p)\left(\hat{V}^{I L}(U)-U\right) \\
& +f(1-\tilde{\eta}(U))(1-q)\left(\tilde{V}^{J L}(U)-U\right) \\
& \left.+(1-f)(1-\hat{\eta}(U))(1-q)\left(\hat{V}^{J L}(U)-U\right)\right] \\
& =l\left[f \tilde{\eta}(U)(1-p)\left(\frac{p R-p \tilde{r}^{I L}(U)}{1-\delta p}-\frac{(1-\delta) U}{1-\delta p}\right)\right. \\
& +(1-f) \hat{\eta}(U)(1-p)\left(\frac{p R-\rho}{1-\delta p}-\frac{(1-\delta) U}{1-\delta p}\right) \\
& +f(1-\tilde{\eta}(U))(1-q)\left(\frac{p R-q \tilde{r}^{J L}(U, S)}{1-\delta q}-\frac{(1-\delta) U}{1-\delta q}\right) \\
& \left.+(1-f)(1-\hat{\eta}(U))(1-q)\left(\frac{p R-\rho}{1-\delta q}-\frac{(1-\delta) U}{1-\delta q}\right)\right]
\end{aligned}
$$

where the last line uses the definitions of $V^{I L}$ and $V^{J L}$. If we assume that 
$S \leq \bar{S}(U)$, so that $\tilde{r}^{J L}(U, S)=r_{I C 2}(U, S)$, then we have:

$$
\begin{aligned}
U(1-l)(1-\delta) & =l[f \tilde{\eta}(U)(1-p)(p R-(1-\delta) U) \\
& +(1-f) \hat{\eta}(U)(1-p)\left(\frac{p R-\rho}{1-\delta p}-\frac{(1-\delta) U}{1-\delta p}\right) \\
& +f(1-\tilde{\eta}(U))(1-q)\left(\frac{2}{2-\delta q}(p R-(1-\delta) U)-\frac{\delta q}{2-\delta q} S\right) \\
& \left.+(1-f)(1-\hat{\eta}(U))(1-q)\left(\frac{p R-\rho}{1-\delta q}-\frac{(1-\delta) U}{1-\delta q}\right)\right]
\end{aligned}
$$

so

$$
\begin{aligned}
& U(1-\delta)\left[(1-l)+l\left(f \tilde{\eta}(U)(1-p)+f(1-\tilde{\eta}(U)) \frac{2(1-q)}{2-\delta q}\right.\right. \\
& \left.\left.+(1-f) \hat{\eta}(U) \frac{1-p}{1-\delta p}+(1-f)(1-\hat{\eta}(U)) \frac{1-q}{1-\delta q}\right)\right] \\
& =l[f \tilde{\eta}(U)(1-p) p R \\
& +(1-f) \hat{\eta}(U)(1-p)\left(\frac{p R-\rho}{1-\delta p}\right) \\
& +f(1-\tilde{\eta}(U))(1-q)\left(\frac{2}{2-\delta q} p R-\frac{\delta q}{2-\delta q} S\right) \\
& \left.+(1-f)(1-\hat{\eta}(U))(1-q)\left(\frac{p R-\rho}{1-\delta q}\right)\right]
\end{aligned}
$$

and therefore:

$$
\begin{aligned}
U & =\frac{A}{B} \\
A & =l[f \tilde{\eta}(U)(1-p) p R \\
& +(1-f) \hat{\eta}(U)(1-p)\left(\frac{p R-\rho}{1-\delta p}\right) \\
& +f(1-\tilde{\eta}(U))(1-q)\left(\frac{2}{2-\delta q} p R-\frac{\delta q}{2-\delta q} S\right) \\
& \left.+(1-f)(1-\hat{\eta}(U))(1-q)\left(\frac{p R-\rho}{1-\delta q}\right)\right]>0 \\
B & =(1-\delta)\left[(1-l)+l\left(f \tilde{\eta}(U)(1-p)+f(1-\tilde{\eta}(U)) \frac{2(1-q)}{2-\delta q}\right.\right. \\
& \left.\left.+(1-f) \hat{\eta}(U) \frac{1-p}{1-\delta p}+(1-f)(1-\hat{\eta}(U)) \frac{1-q}{1-\delta q}\right)\right]>0
\end{aligned}
$$

where the first inequality relies on $S \leq \bar{S}(U)$ which implies

$$
2 p R-\delta q S \geq(2-\delta q) p R+\delta q(1-\delta) U>0
$$


Then, holding $\hat{\eta}$ and $\tilde{\eta}$ constant:

$$
\frac{\partial U}{\partial l}=\frac{1}{B^{2}}\left(B \frac{\partial A}{\partial l}-A \frac{\partial B}{\partial l}\right)
$$

It is obvious that $\frac{\partial A}{\partial l}>0$ since $A$ is positive and proportional to $l$. And:

$$
\begin{aligned}
\frac{\partial B}{\partial l} & =(1-\delta)\left(f \tilde{\eta}(U)(1-p)+f(1-\tilde{\eta}(U)) \frac{2(1-q)}{2-\delta q}\right. \\
& \left.+(1-f) \hat{\eta}(U) \frac{1-p}{1-\delta p}+(1-f)(1-\hat{\eta}(U)) \frac{1-q}{1-\delta q}-1\right)<0
\end{aligned}
$$

so $\frac{\partial U}{\partial l}>0$.

If instead we assume $S>\bar{S}(U)$ then

$$
\begin{aligned}
U(1-l)(1-\delta) & =l[f \tilde{\eta}(U)(1-p)(p R-(1-\delta) U) \\
& +(1-f) \hat{\eta}(U)(1-p)\left(\frac{p R-\rho}{1-\delta p}-\frac{(1-\delta) U}{1-\delta p}\right) \\
& +f(1-\tilde{\eta}(U))(1-q)(p R-(1-\delta) U) \\
& \left.+(1-f)(1-\hat{\eta}(U))(1-q)\left(\frac{p R-\rho}{1-\delta q}-\frac{(1-\delta) U}{1-\delta q}\right)\right]
\end{aligned}
$$

The remaining steps go through much as before. 


\section{Appendix C. Additional figures and tables}

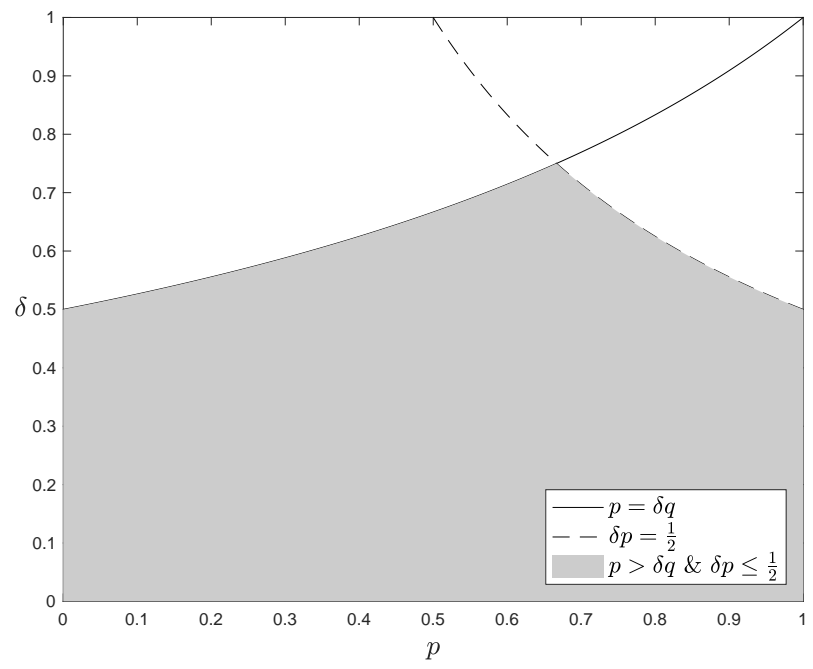

Figure C.1: Values of $p$ and $\delta$ consistent with Assumptions 1 and 3 . 


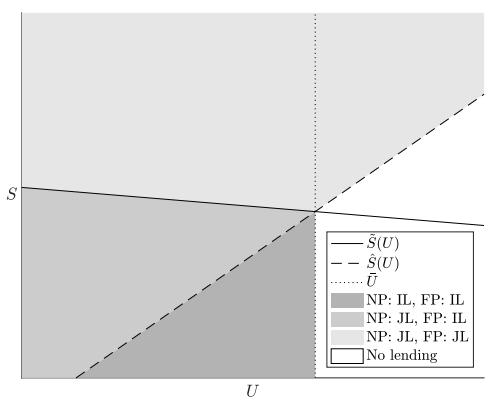

(a) Benchmark

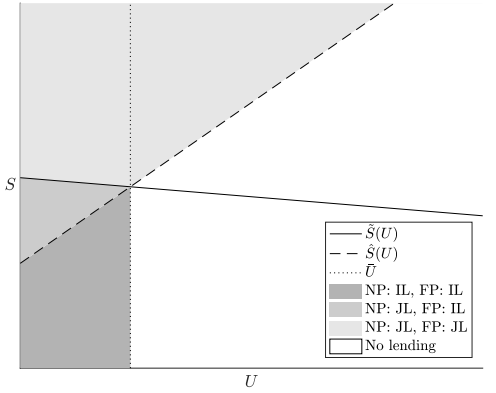

(b) High $\rho$

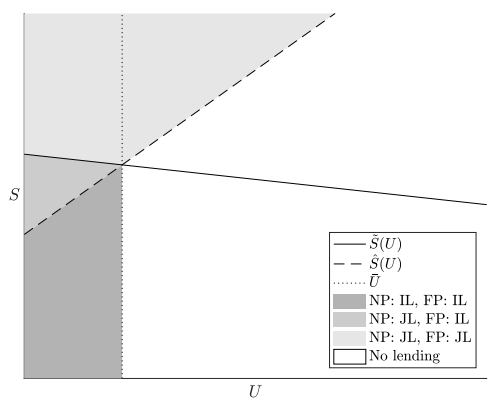

(d) Low $\delta$

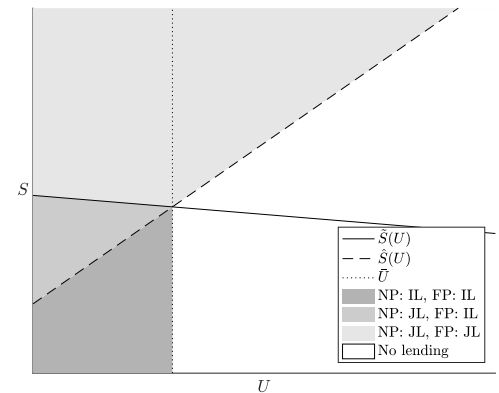

(c) Low $R$

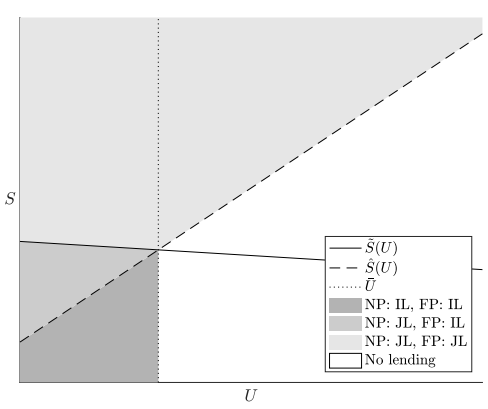

(e) Low $p$

Figure C.2: Contract regions for varying parameters 

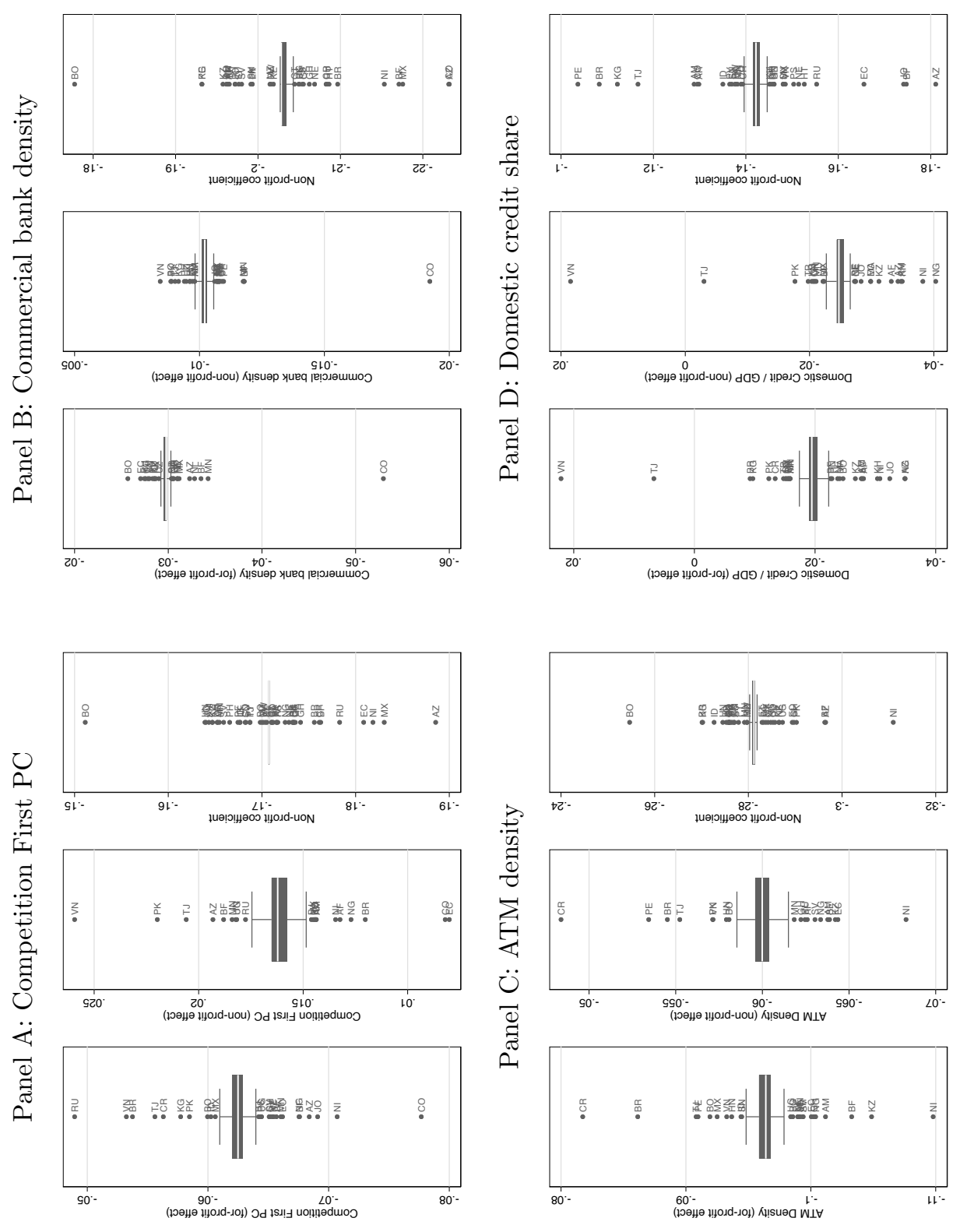

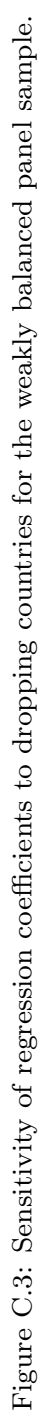



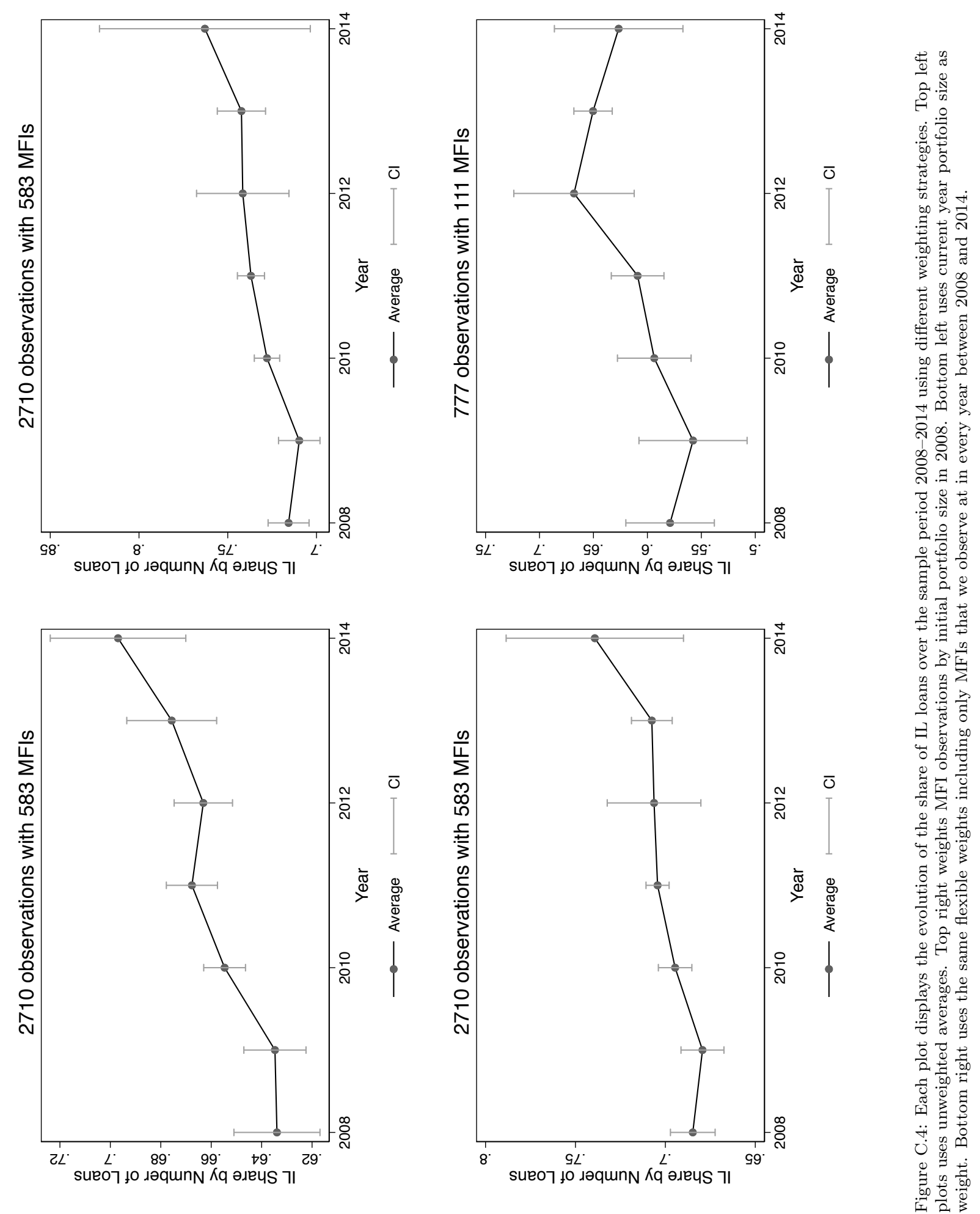

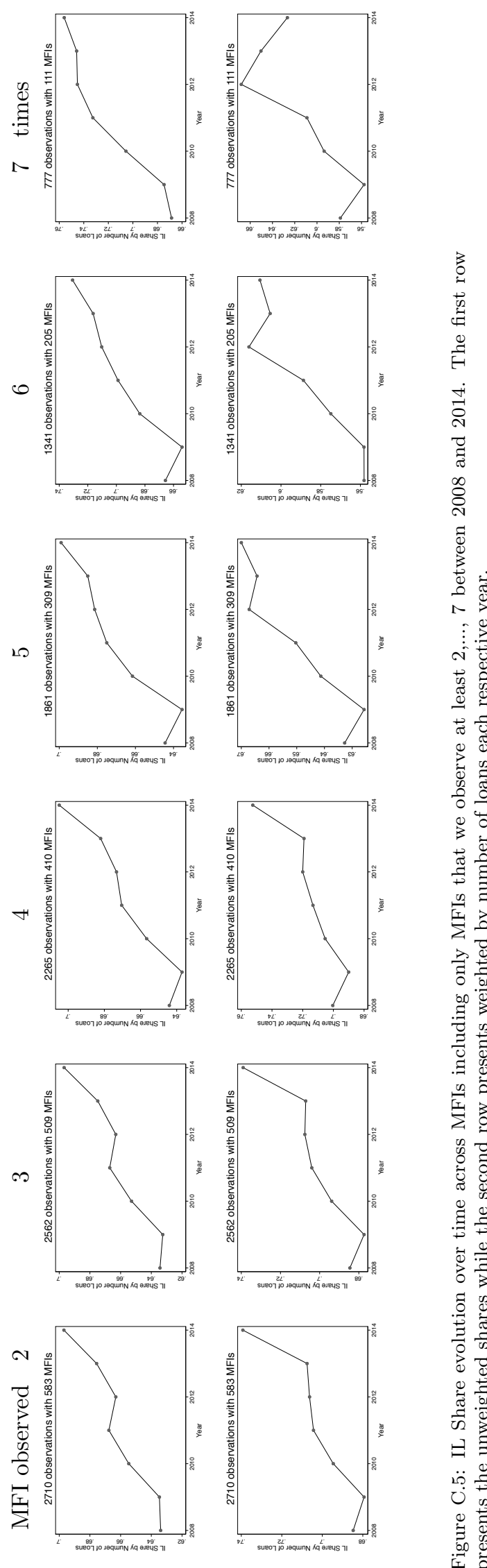

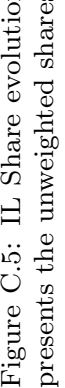


Table C.1: Non Profit Status and Legal Status

\begin{tabular}{llll}
\hline & For-Profit & Non-Profit & Total \\
\hline Legal Status & & & \\
Bank & 199 & 4 & 203 \\
Credit Union / Cooperative & 89 & 358 & 447 \\
NBFI & 569 & 106 & 675 \\
NGO & 44 & 590 & 634 \\
Other & 31 & 10 & 41 \\
Rural Bank & 108 & 2 & 110 \\
Total & & & \\
\hline
\end{tabular}

Notes: MFIs by legal status of MFIs that ever reported to the MIX Market. 
Table C.2: Additional country-level controls, IL shares by number of loans

\begin{tabular}{|c|c|c|c|c|c|c|}
\hline & \multicolumn{3}{|c|}{ Fully Balanced } & \multicolumn{3}{|c|}{ Weakly Balanced } \\
\hline & (1) & $(2)$ & (3) & $(4)$ & $(5)$ & (6) \\
\hline Competition First PC & $\begin{array}{c}-0.056^{* *} \\
(0.023)\end{array}$ & $\begin{array}{c}-0.062^{* * *} \\
(0.017)\end{array}$ & $\begin{array}{c}-0.068^{* * *} \\
(0.013)\end{array}$ & $\begin{array}{l}-0.018 \\
(0.041)\end{array}$ & $\begin{array}{l}-0.039 \\
(0.024)\end{array}$ & $\begin{array}{c}-0.056^{* * *} \\
(0.018)\end{array}$ \\
\hline Non Profit & $\begin{array}{l}-0.129 \\
(0.083)\end{array}$ & $\begin{array}{c}-0.139^{* *} \\
(0.057)\end{array}$ & & $\begin{array}{c}-0.134^{* * *} \\
(0.038)\end{array}$ & $\begin{array}{c}-0.156^{* * *} \\
(0.035)\end{array}$ & \\
\hline Non Profit $\mathrm{x}$ Competition First PC & $\begin{array}{c}0.021 \\
(0.057)\end{array}$ & $\begin{array}{c}0.075^{* *} \\
(0.028)\end{array}$ & $\begin{array}{c}0.092^{* * *} \\
(0.030)\end{array}$ & $\begin{array}{l}-0.004 \\
(0.045)\end{array}$ & $\begin{array}{c}0.056 \\
(0.038)\end{array}$ & $\begin{array}{c}0.071^{* *} \\
(0.027)\end{array}$ \\
\hline \multicolumn{7}{|l|}{ Further Interactions: } \\
\hline Urban population share & $\begin{array}{c}-0.005 \\
(0.004)\end{array}$ & $\begin{array}{c}-0.014 \\
(0.009)\end{array}$ & $\begin{array}{c}-0.014^{*} \\
(0.008)\end{array}$ & $\begin{array}{l}-0.002 \\
(0.002)\end{array}$ & $\begin{array}{c}-0.017^{*} \\
(0.010)\end{array}$ & $\begin{array}{c}-0.014 \\
(0.011)\end{array}$ \\
\hline Non Profit $\mathrm{x}$ Urban population share & $\begin{array}{l}-0.001 \\
(0.005)\end{array}$ & $\begin{array}{c}0.011^{* *} \\
(0.005)\end{array}$ & $\begin{array}{l}-0.003 \\
(0.021)\end{array}$ & $\begin{array}{l}-0.002 \\
(0.003)\end{array}$ & $\begin{array}{c}-0.003 \\
(0.003)\end{array}$ & $\begin{array}{c}0.007 \\
(0.020)\end{array}$ \\
\hline Mobile Phones/100 people & $\begin{array}{c}-0.001 \\
(0.001)\end{array}$ & $\begin{array}{c}-0.000 \\
(0.000)\end{array}$ & $\begin{array}{c}0.000 \\
(0.000)\end{array}$ & $\begin{array}{c}0.000 \\
(0.001)\end{array}$ & $\begin{array}{l}-0.000 \\
(0.000)\end{array}$ & $\begin{array}{c}-0.000 \\
(0.000)\end{array}$ \\
\hline Non Profit x Mobile Phones/100 people & $\begin{array}{c}-0.002 \\
(0.002)\end{array}$ & $\begin{array}{c}-0.001 \\
(0.002)\end{array}$ & $\begin{array}{l}-0.000 \\
(0.001)\end{array}$ & $\begin{array}{c}-0.004^{* * * *} \\
(0.001)\end{array}$ & $\begin{array}{c}-0.002^{* *} \\
(0.001)\end{array}$ & $\begin{array}{c}0.000 \\
(0.001)\end{array}$ \\
\hline Industrial sector share in GDP & $\begin{array}{l}-0.002 \\
(0.010)\end{array}$ & $\begin{array}{c}-0.011 \\
(0.010)\end{array}$ & $\begin{array}{c}-0.015^{* *} \\
(0.007)\end{array}$ & $\begin{array}{l}-0.002 \\
(0.004)\end{array}$ & $\begin{array}{c}-0.009^{* *} \\
(0.004)\end{array}$ & $\begin{array}{c}-0.005 \\
(0.005)\end{array}$ \\
\hline Non Profit x Industrial sector share in GDP & $\begin{array}{l}-0.015 \\
(0.017)\end{array}$ & $\begin{array}{c}-0.023^{* *} \\
(0.010)\end{array}$ & $\begin{array}{l}-0.025 \\
(0.016)\end{array}$ & $\begin{array}{l}-0.010 \\
(0.007)\end{array}$ & $\begin{array}{l}-0.004 \\
(0.008)\end{array}$ & $\begin{array}{l}-0.013^{*} \\
(0.007)\end{array}$ \\
\hline Service sector share in GDP & $\begin{array}{c}0.001 \\
(0.009)\end{array}$ & $\begin{array}{c}-0.006 \\
(0.008)\end{array}$ & $\begin{array}{c}-0.012^{* *} \\
(0.005)\end{array}$ & $\begin{array}{c}0.002 \\
(0.004)\end{array}$ & $\begin{array}{c}-0.011^{* *} \\
(0.005)\end{array}$ & $\begin{array}{l}-0.009^{*} \\
(0.005)\end{array}$ \\
\hline Non Profit x Service sector share in GDP & $\begin{array}{l}-0.013 \\
(0.016)\end{array}$ & $\begin{array}{c}0.003 \\
(0.009)\end{array}$ & $\begin{array}{c}-0.014 \\
(0.008)\end{array}$ & $\begin{array}{c}-0.010^{*} \\
(0.006)\end{array}$ & $\begin{array}{l}-0.006 \\
(0.007)\end{array}$ & $\begin{array}{c}-0.009 \\
(0.007)\end{array}$ \\
\hline Development Aid as share of GDP & $\begin{array}{c}0.000 \\
(0.000)\end{array}$ & $\begin{array}{c}0.000 \\
(0.000)\end{array}$ & $\begin{array}{c}0.000 \\
(0.000)\end{array}$ & $\begin{array}{l}-0.000 \\
(0.000)\end{array}$ & $\begin{array}{c}0.000 \\
(0.000)\end{array}$ & $\begin{array}{c}0.000 \\
(0.000)\end{array}$ \\
\hline Non Profit x Development Aid as share of GDP & $\begin{array}{c}-0.000 \\
(0.000)\end{array}$ & $\begin{array}{c}-0.000 \\
(0.000)\end{array}$ & $\begin{array}{c}0.000 \\
(0.000)\end{array}$ & $\begin{array}{l}-0.000 \\
(0.000)\end{array}$ & $\begin{array}{c}0.000 \\
(0.000)\end{array}$ & $\begin{array}{c}0.000 \\
(0.000)\end{array}$ \\
\hline GDP per capita & $\begin{array}{l}0.000^{*} \\
(0.000)\end{array}$ & $\begin{array}{c}-0.000^{*} \\
(0.000)\end{array}$ & $\begin{array}{c}-0.000 \\
(0.000)\end{array}$ & $\begin{array}{c}-0.000 \\
(0.000)\end{array}$ & $\begin{array}{c}-0.000 \\
(0.000)\end{array}$ & $\begin{array}{c}-0.000^{* *} \\
(0.000)\end{array}$ \\
\hline Non Profit $\mathrm{x}$ GDP per capita & $\begin{array}{c}0.000 \\
(0.000)\end{array}$ & $\begin{array}{c}-0.000 \\
(0.000)\end{array}$ & $\begin{array}{c}0.000 \\
(0.000)\end{array}$ & $\begin{array}{c}0.000^{* *} \\
(0.000)\end{array}$ & $\begin{array}{c}0.000^{* *} \\
(0.000)\end{array}$ & $\begin{array}{c}0.000 \\
(0.000)\end{array}$ \\
\hline \multicolumn{7}{|l|}{ Joint test: } \\
\hline Comp + Non-Profit $\mathrm{x}$ Comp $=0 ?$ & $\begin{array}{c}-.035 \\
(.0568)\end{array}$ & $\begin{array}{c}.013 \\
(.0226)\end{array}$ & $\begin{array}{c}.024 \\
(.0241)\end{array}$ & $\begin{array}{c}-.022 \\
(.0505)\end{array}$ & $\begin{array}{c}.017 \\
(.0257)\end{array}$ & $\begin{array}{c}.016 \\
(.0212)\end{array}$ \\
\hline MFIs & 108 & 108 & 108 & 521 & 521 & 521 \\
\hline Countries & 35 & 35 & 35 & 75 & 75 & 75 \\
\hline Observations & 744 & 744 & 744 & 2406 & 2406 & 2406 \\
\hline $\begin{array}{l}\text { Year FE } \\
\text { Region FE }\end{array}$ & $\begin{array}{l}\mathrm{X} \\
\mathrm{X}\end{array}$ & $\mathrm{X}$ & $\mathrm{X}$ & $\begin{array}{l}\mathrm{X} \\
\mathrm{X}\end{array}$ & $\mathrm{X}$ & $\mathrm{X}$ \\
\hline Country FE & & $\mathrm{X}$ & & & $\mathrm{X}$ & \\
\hline MFI FE & & & $\mathrm{X}$ & & & $\mathrm{X}$ \\
\hline
\end{tabular}


Table C.3: Additional fixed effects and MFI-level controls

\begin{tabular}{|c|c|c|c|c|c|c|c|c|}
\hline & \multicolumn{4}{|c|}{ Fully Balanced } & \multicolumn{4}{|c|}{ Weakly Balanced } \\
\hline & (1) & $(2)$ & (3) & (4) & (5) & (6) & (7) & $(8)$ \\
\hline Non Profit & $\begin{array}{l}-0.117 \\
(0.081)\end{array}$ & & $\begin{array}{c}-0.124^{*} \\
(0.071)\end{array}$ & & $\begin{array}{c}-0.175^{* * *} \\
(0.039)\end{array}$ & & $\begin{array}{c}-0.145^{* * *} \\
(0.032)\end{array}$ & \\
\hline Non Profit $\mathrm{x}$ Competition First PC & $\begin{array}{l}0.101^{*} \\
(0.054)\end{array}$ & $\begin{array}{c}0.087^{* * *} \\
(0.027)\end{array}$ & $\begin{array}{c}0.072 \\
(0.043)\end{array}$ & $\begin{array}{c}0.084^{* *} \\
(0.032)\end{array}$ & $\begin{array}{c}0.092^{* * * *} \\
(0.028)\end{array}$ & $\begin{array}{c}0.078^{* * *} \\
(0.028)\end{array}$ & $\begin{array}{c}0.073^{* * *} \\
(0.025)\end{array}$ & $\begin{array}{c}0.070^{* *} \\
(0.028)\end{array}$ \\
\hline MFIs & 98 & 98 & 98 & 98 & 527 & 520 & 525 & 503 \\
\hline Countries & 24 & 24 & 24 & 24 & 61 & 59 & 60 & 56 \\
\hline Observations & 678 & 678 & 669 & 669 & 2429 & 2421 & 2326 & 2301 \\
\hline MFI FE & & $\mathrm{X}$ & & $\mathrm{X}$ & & $\mathrm{X}$ & & $\mathrm{X}$ \\
\hline Country x Year FE & $\mathrm{X}$ & $\mathrm{X}$ & $\mathrm{X}$ & $\mathrm{X}$ & $\mathrm{X}$ & $\mathrm{X}$ & $\mathrm{X}$ & $\mathrm{X}$ \\
\hline MFI Controls & & & $\mathrm{X}$ & $\mathrm{X}$ & & & $\mathrm{X}$ & $\mathrm{X}$ \\
\hline
\end{tabular}

Notes: The dependent variable is the share of individual liability loans provided by an MFI as measured by Number of Loans. Fully balanced refers to a balanced dataset for which lending methodology data is available for the period 2008-2014, while weakly balanced includes only MFIs that report this information at least twice. Controls include Diamonds, Capital to Asset Ratio, Debt to equity ratio, Average loan balance per borrower, Return on assets, Financial revenue/Assets, Yield on gross portfolio (nominal), Financial expense/assets, Operating expense/assets. Standard errors in parentheses are clustered at the country level, with stars indicating ${ }^{* * *} p<0.01,{ }^{* *} p<0.05,{ }^{*} p<0.1$. 
Table C.4: Cost regressions

\begin{tabular}{|c|c|c|c|c|c|c|}
\hline \multirow{2}{*}{ Panel A: Operating expense } & \multicolumn{3}{|c|}{ Fully Balanced } & \multicolumn{3}{|c|}{ Weakly Balanced } \\
\hline & (1) & $(2)$ & $(3)$ & $(4)$ & (5) & $(6)$ \\
\hline Competition First PC & $\begin{array}{c}-0.002 \\
(0.041)\end{array}$ & $\begin{array}{c}-0.065^{* *} \\
(0.032)\end{array}$ & $\begin{array}{c}-0.067^{* * *} \\
(0.012)\end{array}$ & $\begin{array}{l}-0.030 \\
(0.032)\end{array}$ & $\begin{array}{c}-0.070^{* *} \\
(0.028)\end{array}$ & $\begin{array}{c}-0.061^{* * *} \\
(0.015)\end{array}$ \\
\hline Non Profit & $\begin{array}{c}-0.134^{*} \\
(0.073)\end{array}$ & $\begin{array}{l}-0.121 \\
(0.081)\end{array}$ & & $\begin{array}{c}-0.133^{* * *} \\
(0.042)\end{array}$ & $\begin{array}{c}-0.164^{* * *} \\
(0.036)\end{array}$ & \\
\hline Non Profit $\times$ Competition First PC & $\begin{array}{c}0.032 \\
(0.051)\end{array}$ & $\begin{array}{c}0.083 \\
(0.049)\end{array}$ & $\begin{array}{c}0.077^{* * *} \\
(0.023)\end{array}$ & $\begin{array}{c}0.027 \\
(0.026)\end{array}$ & $\begin{array}{c}0.078^{* * *} \\
(0.025)\end{array}$ & $\begin{array}{c}0.067^{* * *} \\
(0.019)\end{array}$ \\
\hline Operating expense (\% of assets) & $\begin{array}{c}-0.093 \\
(0.083)\end{array}$ & $\begin{array}{c}-0.188^{* *} \\
(0.080)\end{array}$ & $\begin{array}{l}-0.016 \\
(0.024)\end{array}$ & $\begin{array}{c}-0.107^{* * *} \\
(0.030)\end{array}$ & $\begin{array}{c}-0.109^{* * *} \\
(0.021)\end{array}$ & $\begin{array}{l}-0.019 \\
(0.015)\end{array}$ \\
\hline Non Profit $\times$ Operating expense $(\%$ of assets $)$ & $\begin{array}{c}-0.066 \\
(0.102)\end{array}$ & $\begin{array}{c}0.052 \\
(0.088)\end{array}$ & $\begin{array}{c}0.013 \\
(0.026)\end{array}$ & $\begin{array}{c}-0.022 \\
(0.036)\end{array}$ & $\begin{array}{l}-0.015 \\
(0.030)\end{array}$ & $\begin{array}{c}0.013 \\
(0.018)\end{array}$ \\
\hline $\begin{array}{l}\text { Countries } \\
\text { MFIs } \\
\text { Observations }\end{array}$ & $\begin{array}{c}37 \\
111 \\
761\end{array}$ & $\begin{array}{c}37 \\
111 \\
761\end{array}$ & $\begin{array}{c}37 \\
111 \\
761\end{array}$ & $\begin{array}{c}81 \\
548 \\
2479\end{array}$ & $\begin{array}{c}81 \\
548 \\
2479\end{array}$ & $\begin{array}{c}81 \\
548 \\
2479\end{array}$ \\
\hline Panel B: Financial expense & (1) & $(2)$ & $(3)$ & (4) & (5) & $(6)$ \\
\hline Competition First PC & $\begin{array}{l}-0.021 \\
(0.042)\end{array}$ & $\begin{array}{c}-0.071^{* *} \\
(0.027)\end{array}$ & $\begin{array}{c}-0.068^{* * *} \\
(0.011)\end{array}$ & $\begin{array}{l}-0.039 \\
(0.035)\end{array}$ & $\begin{array}{c}-0.067^{* *} \\
(0.026)\end{array}$ & $\begin{array}{c}-0.061^{* * *} \\
(0.015)\end{array}$ \\
\hline Non Profit & $\begin{array}{l}-0.110 \\
(0.074)\end{array}$ & $\begin{array}{l}-0.091 \\
(0.077)\end{array}$ & & $\begin{array}{c}-0.127^{* *} \\
(0.053)\end{array}$ & $\begin{array}{c}-0.179^{* * *} \\
(0.042)\end{array}$ & \\
\hline Non Profit $\times$ Competition First PC & $\begin{array}{c}0.050 \\
(0.055)\end{array}$ & $\begin{array}{c}0.088 * * \\
(0.041)\end{array}$ & $\begin{array}{c}0.078^{* * *} \\
(0.022)\end{array}$ & $\begin{array}{c}0.034 \\
(0.029)\end{array}$ & $\begin{array}{c}0.085^{* * *} \\
(0.026)\end{array}$ & $\begin{array}{c}0.066^{* * *} \\
(0.018)\end{array}$ \\
\hline Financial expense (\% of assets) & $\begin{array}{c}0.037 \\
(0.043)\end{array}$ & $\begin{array}{c}0.056 \\
(0.050)\end{array}$ & $\begin{array}{c}0.003 \\
(0.008)\end{array}$ & $\begin{array}{c}0.006 \\
(0.020)\end{array}$ & $\begin{array}{c}0.006 \\
(0.022)\end{array}$ & $\begin{array}{c}0.005 \\
(0.011)\end{array}$ \\
\hline Non Profit $\times$ Financial expense ( $\%$ of assets) & $\begin{array}{c}-0.011 \\
(0.056)\end{array}$ & $\begin{array}{c}-0.131^{*} \\
(0.065)\end{array}$ & $\begin{array}{l}-0.008 \\
(0.022)\end{array}$ & $\begin{array}{c}0.013 \\
(0.024)\end{array}$ & $\begin{array}{c}0.015 \\
(0.023)\end{array}$ & $\begin{array}{c}0.002 \\
(0.019)\end{array}$ \\
\hline Countries & 37 & 37 & 37 & 81 & 81 & 81 \\
\hline MFIs & 111 & 111 & 111 & 548 & 548 & 548 \\
\hline Observations & 759 & 759 & 759 & 2472 & 2472 & 2472 \\
\hline Year FE & $\mathrm{X}$ & $\mathrm{X}$ & $\mathrm{X}$ & $\mathrm{X}$ & $\mathrm{X}$ & $\mathrm{X}$ \\
\hline Region FE & $\mathrm{X}$ & & & $\mathrm{X}$ & & \\
\hline $\begin{array}{l}\text { Country FE } \\
\text { MFI FE }\end{array}$ & & $\mathrm{X}$ & $\mathrm{X}$ & & $X$ & $\mathrm{X}$ \\
\hline $\begin{array}{l}\text { Notes: The dependent variable is the share of indiv } \\
\text { Strongly balanced refers to a balanced dataset for } \\
\text { 2014, while weakly balanced includes only MFIs that } \\
\text { expenses in a financial year as a share of the value of } \\
\text { as a share of the value of assets in Panel B. Standard } \\
{ }^{* * *} p<0.01,{ }^{* *} p<0.05,{ }^{*} p<0.1 \text {. }\end{array}$ & $\begin{array}{l}\text { lual liabi } \\
\text { iich lend } \\
\text { eport thi } \\
\text { sets at th } \\
\text { rrors in }\end{array}$ & $\begin{array}{l}\text { y loans pr } \\
\text { methodo } \\
\text { nformation } \\
\text { end of a ye } \\
\text { rentheses a }\end{array}$ & $\begin{array}{l}\text { vided by an } \\
\text { ogy data is } \\
\text { at least twi } \\
\text { ar in panel A } \\
\text { ce clustered }\end{array}$ & $\begin{array}{l}\text { MFI as mea } \\
\text { vailable for } \\
\text { The costs } \\
\text { while they } \\
\text { the countr }\end{array}$ & $\begin{array}{l}\text { red by Num } \\
\text { years betw } \\
\text { easures are } \\
\text { us on the co } \\
\text { evel, with st }\end{array}$ & $\begin{array}{l}\text { oer of Loans. } \\
\text { een } 2008 \text { and } \\
\text { he Operating } \\
\text { t of financing } \\
\text { ars indicating }\end{array}$ \\
\hline
\end{tabular}


Table C.5: IL Share by Number of Loans: Robustness to Other Competition Proxy Variables

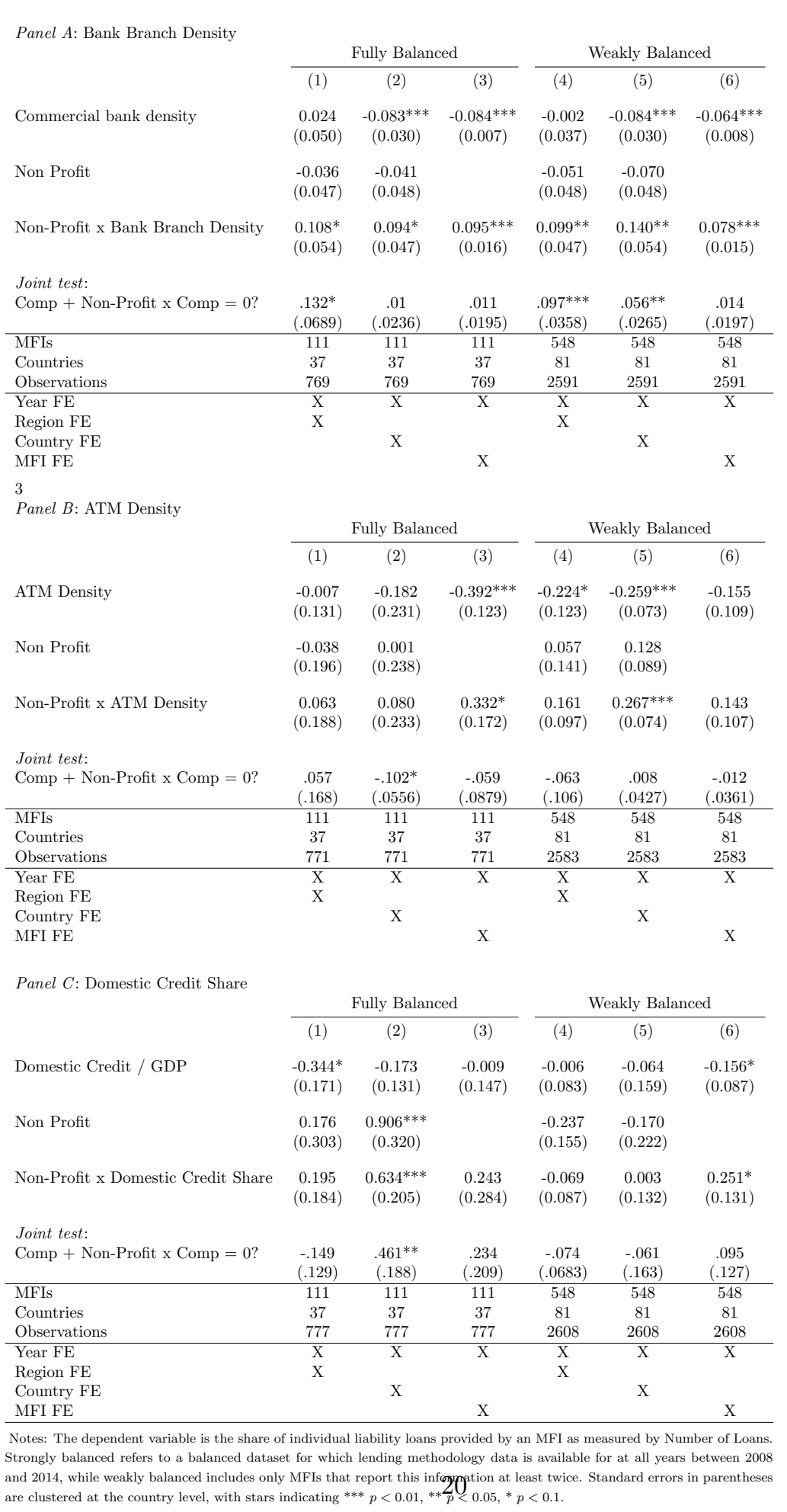


Table C.6: Controlling for Regulatory changes: Removing MFIs that switched Legal Status and controlling flexibly for status: Non Profit Status, Competition and IL Lending

\begin{tabular}{|c|c|c|c|c|c|c|}
\hline \multirow[t]{2}{*}{ Panel A: Removing Legal Status changes } & \multicolumn{3}{|c|}{ Fully Balanced } & \multicolumn{3}{|c|}{ Weakly Balanced } \\
\hline & (1) & $(2)$ & $(3)$ & (4) & (5) & (6) \\
\hline Competition First PC & $\begin{array}{c}0.001 \\
(0.048)\end{array}$ & $\begin{array}{l}-0.058 \\
(0.050)\end{array}$ & $\begin{array}{c}-0.060^{* * *} \\
(0.013)\end{array}$ & $\begin{array}{l}-0.037 \\
(0.040)\end{array}$ & $\begin{array}{c}-0.064^{*} \\
(0.032)\end{array}$ & $\begin{array}{c}-0.065^{* * *} * \\
(0.016)\end{array}$ \\
\hline Non Profit & $\begin{array}{c}-0.132 \\
(0.113)\end{array}$ & $\begin{array}{l}-0.109 \\
(0.163)\end{array}$ & & $\begin{array}{c}-0.138^{* *} \\
(0.055)\end{array}$ & $\begin{array}{c}-0.205^{* * *} \\
(0.048)\end{array}$ & \\
\hline Non Profit x Competition First PC & $\begin{array}{c}0.095 \\
(0.073)\end{array}$ & $\begin{array}{c}0.067 \\
(0.082)\end{array}$ & $\begin{array}{c}0.072^{* * *} \\
(0.014)\end{array}$ & $\begin{array}{c}0.037 \\
(0.031)\end{array}$ & $\begin{array}{c}0.086^{* * *} \\
(0.033)\end{array}$ & $\begin{array}{c}0.073^{* * *} \\
(0.020)\end{array}$ \\
\hline \multicolumn{7}{|l|}{ Joint test: } \\
\hline Comp + Non-Profit $\times$ Comp $=0 ?$ & $\begin{array}{c}.095^{*} \\
(.0554) \\
\end{array}$ & $\begin{array}{c}.009 \\
(.0376) \\
\end{array}$ & $\begin{array}{c}.011 \\
(.0208) \\
\end{array}$ & $\begin{array}{c}0 \\
(.0402) \\
\end{array}$ & $\begin{array}{c}.022 \\
(.0184) \\
\end{array}$ & $\begin{array}{c}.008 \\
(.0174) \\
\end{array}$ \\
\hline MFIs & 71 & 71 & 71 & 422 & 422 & 422 \\
\hline Countries & 25 & 25 & 25 & 79 & 79 & 79 \\
\hline Observations & 496 & 496 & 496 & 1919 & 1919 & 1919 \\
\hline Year FE & $\mathrm{X}$ & $\mathrm{X}$ & $\mathrm{X}$ & $\mathrm{X}$ & $\mathrm{X}$ & $\mathrm{X}$ \\
\hline Region FE & $\mathrm{X}$ & & & $\mathrm{X}$ & & \\
\hline Country FE & & $\mathrm{X}$ & & & $\mathrm{X}$ & \\
\hline MFI FE & & & $\mathrm{X}$ & & & $\mathrm{X}$ \\
\hline \multirow[t]{2}{*}{ Panel B: Region specific legal status FE } & \multicolumn{3}{|c|}{ Fully Balanced } & \multicolumn{3}{|c|}{ Weakly Balanced } \\
\hline & (1) & (2) & (3) & (4) & (5) & (6) \\
\hline Competition First PC & $\begin{array}{l}-0.028 \\
(0.057)\end{array}$ & $\begin{array}{c}-0.083^{*} \\
(0.046)\end{array}$ & $\begin{array}{c}-0.060^{*} \\
(0.033)\end{array}$ & $\begin{array}{l}-0.025 \\
(0.041)\end{array}$ & $\begin{array}{c}-0.056^{*} \\
(0.028)\end{array}$ & $\begin{array}{c}-0.062^{* * * *} \\
(0.020)\end{array}$ \\
\hline Non Profit & $\begin{array}{l}-0.138 \\
(0.089)\end{array}$ & $\begin{array}{l}-0.088 \\
(0.120)\end{array}$ & & $\begin{array}{c}-0.120^{* *} \\
(0.058)\end{array}$ & $\begin{array}{c}-0.096 \\
(0.060)\end{array}$ & \\
\hline Non Profit x Competition First PC & $\begin{array}{c}0.081 \\
(0.064)\end{array}$ & $\begin{array}{c}0.121 \\
(0.078)\end{array}$ & $\begin{array}{c}0.081 \\
(0.058)\end{array}$ & $\begin{array}{c}0.035 \\
(0.029)\end{array}$ & $\begin{array}{l}0.074^{*} \\
(0.038)\end{array}$ & $\begin{array}{c}0.085^{* *} \\
(0.041)\end{array}$ \\
\hline \multicolumn{7}{|l|}{ Joint test: } \\
\hline Comp + Non-Profit $\mathrm{x}$ Comp $=0 ?$ & $\begin{array}{c}.053 \\
(.0548) \\
\end{array}$ & $\begin{array}{c}.038 \\
(.0368)\end{array}$ & $\begin{array}{c}.022 \\
(.0315)\end{array}$ & $\begin{array}{c}.01 \\
(.0334)\end{array}$ & $\begin{array}{c}.018 \\
(.018)\end{array}$ & $\begin{array}{c}.022 \\
(.0256)\end{array}$ \\
\hline MFIs & 111 & 111 & 111 & 548 & 548 & 548 \\
\hline Countries & 37 & 37 & 37 & 81 & 81 & 81 \\
\hline Observations & 769 & 769 & 769 & 2573 & 2573 & 2573 \\
\hline Region x Legal Status x Year FE & $\mathrm{X}$ & $\mathrm{X}$ & $\mathrm{X}$ & $\mathrm{X}$ & $\mathrm{X}$ & $\mathrm{X}$ \\
\hline Country FE & & $\mathrm{X}$ & & & $\mathrm{X}$ & \\
\hline MFI FE & & & $\mathrm{X}$ & & & $\mathrm{X}$ \\
\hline
\end{tabular}

Notes: The dependent variable is the share of individual liability loans provided by an MFI as measured by Number of Loans. Strongly balanced refers to a balanced dataset for which lending methodology data is available for each year between 2008 and 2014, while weakly balanced includes only MFIs that report this information at least twice. We drop MFIs whose legal status has changed. Standard errors in parentheses are clustered at the country level, with stars indicating $* * * p<0.01,{ }^{* *} p<0.05,{ }^{*} p<0.1$. 
Panel A: Drop MFI that ever report $100 \%$ JL/IL

\begin{tabular}{ccccccc}
\multicolumn{3}{c}{ Fully Balanced } & & \multicolumn{3}{c}{ Weakly Balanced } \\
\cline { 1 - 2 } \cline { 5 - 6 }$(1)$ & $(2)$ & $(3)$ & & $(4)$ & $(5)$ & $(6)$ \\
$-0.229^{* * *}$ & -0.115 & 0.062 & & $-0.180^{* * *}$ & -0.025 & -0.021 \\
$(0.071)$ & $(0.118)$ & $(0.132)$ & $(0.038)$ & $(0.048)$ & $(0.053)$ \\
& & & & & & \\
0.033 & 0.055 & & -0.035 & $-0.112^{*}$ & \\
$(0.084)$ & $(0.097)$ & & $(0.061)$ & $(0.058)$ & \\
$0.195^{*}$ & 0.172 & -0.006 & & $0.123^{* *}$ & $0.101^{* *}$ & 0.094 \\
$(0.098)$ & $(0.104)$ & $(0.130)$ & $(0.052)$ & $(0.042)$ & $0.058)$
\end{tabular}

Joint test:

Comp + Non-Profit $\mathrm{x}$ Comp $=0$ ?

$\begin{array}{llllll}-.035 & .057 & .056 & -.056 & .076^{*} & .074^{*}\end{array}$

\begin{tabular}{llllll}
$(.0741)$ & $(.0458)$ & $(.043)$ & $(.0383)$ & $(.0442)$ & $(.0394)$ \\
\hline
\end{tabular}

MFIs

$\begin{array}{llllll}47 & 47 & 47 & 215 & 215 & 215\end{array}$

Countries

Observations

Year FE

Region FE

Country FE

MFI FE

$\begin{array}{cccccc}20 & 20 & 20 & 56 & 56 & 56 \\ 322 & 322 & 322 & 1019 & 1019 & 1019 \\ \mathrm{X} & \mathrm{X} & \mathrm{X} & \mathrm{X} & \mathrm{X} & \mathrm{X} \\ \mathrm{X} & & & \mathrm{X} & & \\ & \mathrm{X} & & & \mathrm{X} & \\ & & \mathrm{X} & & & \mathrm{X}\end{array}$

Panel B: Drop MFI years that report $100 \%$ JL/IL

\begin{tabular}{|c|c|c|c|c|c|}
\hline \multicolumn{3}{|c|}{ Fully Balanced } & \multicolumn{3}{|c|}{ Weakly Balanced } \\
\hline (1) & $(2)$ & (3) & (4) & $(5)$ & (6) \\
\hline $\begin{array}{l}-0.070 \\
(0.081)\end{array}$ & $\begin{array}{l}-0.037 \\
(0.051)\end{array}$ & $\begin{array}{c}0.010 \\
(0.032)\end{array}$ & $\begin{array}{c}-0.111^{* *} \\
(0.055)\end{array}$ & $\begin{array}{c}0.002 \\
(0.038)\end{array}$ & $\begin{array}{l}-0.015 \\
(0.028)\end{array}$ \\
\hline $\begin{array}{c}-0.173^{*} \\
(0.089)\end{array}$ & $\begin{array}{c}-0.064 \\
(0.090)\end{array}$ & & $\begin{array}{c}-0.143^{* *} \\
(0.061)\end{array}$ & $\begin{array}{c}-0.192^{* * *} \\
(0.046)\end{array}$ & \\
\hline $\begin{array}{c}0.029 \\
(0.076)\end{array}$ & $\begin{array}{c}0.089 \\
(0.075)\end{array}$ & $\begin{array}{c}0.054 \\
(0.038)\end{array}$ & $\begin{array}{c}0.047 \\
(0.044)\end{array}$ & $\begin{array}{c}0.053 \\
(0.037)\end{array}$ & $\begin{array}{c}0.084^{* *} \\
(0.037)\end{array}$ \\
\hline
\end{tabular}

Joint test:

Comp + Non-Profit $\mathrm{x}$ Comp $=0 ?$

$\begin{array}{llllll}-.04 & .052 & .064 & -.063 * * & .054^{*} & .07 * *\end{array}$

MFIs

$\begin{array}{llllll}(.0632) & (.0406) & (.0437) & (.0317) & (.0313) & (.0335)\end{array}$

Countries

Observations

Year FE

Region FE

Country FE

$\begin{array}{cccccc}83 & 83 & 83 & 392 & 392 & 392 \\ 32 & 32 & 32 & 74 & 74 & 74\end{array}$

MFI FE

\begin{tabular}{cccccc}
432 & 432 & 432 & 1454 & 1454 & 1454 \\
\hline $\mathrm{X}$ & $\mathrm{X}$ & $\mathrm{X}$ & $\mathrm{X}$ & $\mathrm{X}$ & $\mathrm{X}$
\end{tabular}

Notes: The dependent variable is the share of individual liability loans provided by an MFI as measured by Number of Loans. Panel A removes MFIs that at any point in time report to only have IL or JL loans, while Panel B only removes the respective years in which this is the case. Strongly balanced refers to a balanced dataset for which lending methodology data is available for each year between 2008 and 2014, while weakly balanced includes only MFIs that report this information at least twice. We drop MFIs whose legal status has changed. Standard errors in parentheses are clustered at the country level, with stars indicating ${ }^{* * *} p<0.01,{ }^{* *} p<0.05,{ }^{*} p<0.1$. 
Table C.8: Correlation between IL share and proxies for social capital on identical samples

Panel $A$ Weakly balanced

(1)

$-0.002$

(0.003)
$(2)$

(3)

(4)

(5)

Urban population share

0.109

Most people can be trusted

(0.173)

Trust people just met

2.368

(2.162)

Trust family members

0.659

(0.472)

Trust people you know

0.377

$(0.364)$

\begin{tabular}{lccccc}
\hline Countries & 80 & 49 & 37 & 37 & 37 \\
MFIs & 541 & 379 & 324 & 324 & 324 \\
Observations & 2535 & 1766 & 1483 & 1483 & 1483 \\
\hline Region FE & $\mathrm{X}$ & $\mathrm{X}$ & $\mathrm{X}$ & $\mathrm{X}$ & $\mathrm{X}$ \\
Year FE & $\mathrm{X}$ & $\mathrm{X}$ & $\mathrm{X}$ & $\mathrm{X}$ & $\mathrm{X}$
\end{tabular}

Panel B Fully balanced

(1)

Urban population share $\quad 0.002$

$$
\text { (0.004) }
$$

Most people can be trusted

Trust people just met

Trust family members

0.074

(0.965)

Trust people you know

$-0.300$

$(0.844)$

\begin{tabular}{lccccc}
\hline Countries & 36 & 26 & 18 & 18 & 18 \\
MFIs & 109 & 67 & 51 & 51 & 51 \\
Observations & 755 & 467 & 357 & 357 & 357 \\
\hline Region FE & $\mathrm{X}$ & $\mathrm{X}$ & $\mathrm{X}$ & $\mathrm{X}$ & $\mathrm{X}$ \\
Year FE & $\mathrm{X}$ & $\mathrm{X}$ & $\mathrm{X}$ & $\mathrm{X}$ & $\mathrm{X}$ \\
\hline
\end{tabular}

Notes: The dependent variable is the share of IL lending. The first trust measure measures the share of respondents that reported that "Most people can be trusted" across all World Values Surveys conducted. Urban population share measures the share of a countries population that lives in urban areas. 